\title{
Comparison of Achievable Magnetic Fields with Superconducting and Cryogenic Permanent Magnet Undulators - A Comprehensive Study of Computed and Measured Values*
}

\author{
Light Source Note: ANL/APS/LS-348 \\ E.R. Moog, R.J. Dejus, and S. Sasaki
Advanced Photon Source, Argonne National Laboratory Argonne, IL 60439

\begin{abstract}
The submitted manuscript has been created by UChicago Argonne, LLC, Operator of Argonne National Laboratory (“Argonne”). Argonne, a U.S. Department of Energy Office of Science laboratory, is operated under Contract No. DE-AC02-06CH11357.

The U.S. Government retains for itself, and others acting on its behalf, a paid-up nonexclusive, irrevocable worldwide license in said article to reproduce, prepare derivative works, distribute copies to the public, and perform publicly and display publicly, by or on behalf of the Government. The Department of Energy will provide public access to these results of federally sponsored research in accordance with the DOE Public Access Plan. http://energy.gov/downloads/doe-public-access-plan.
\end{abstract}

\footnotetext{
* Work supported by the U.S. Department of Energy, Office of Science, under Contract No. DE-AC02-06CH11357.
} 
Comparison of Achievable Magnetic Fields with Superconducting and Cryogenic Permanent Magnet Undulators - A Comprehensive Study of Computed and Measured Values

\author{
Light Source Note: ANL/APS/LS-348 \\ E.R. Moog, R.J. Dejus, and S. Sasaki
}

Revisions: Original release July 17, 2017.

\title{
Contents
}

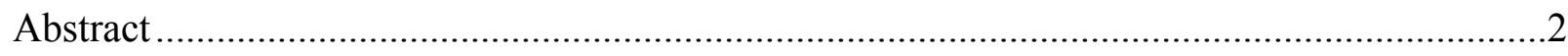



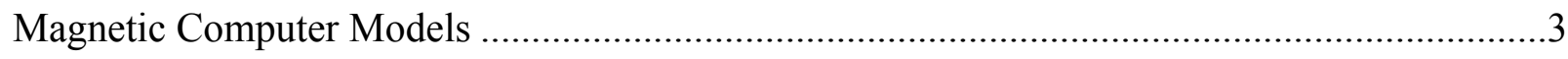

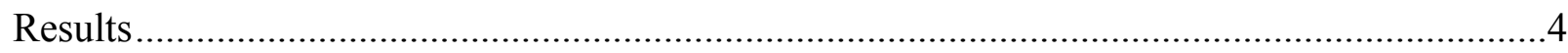

Computed Magnetic Fields of Cryogenic Permanent Magnet Undulators (CPMUs) ...............4

Comparison of Magnetic Fields of CPMUs, Superconducting Undulators (SCUs), and an InVacuum SmCo Undulator (IVU).

First Harmonic Energies and Brightness Tuning Curves for Undulators Installed on APS$\mathrm{U}$

Generic CPMU Model Calculations Compared to Real CPMUs ..........................................15

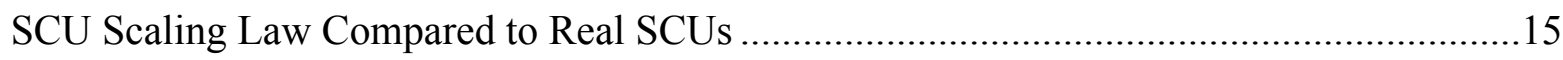

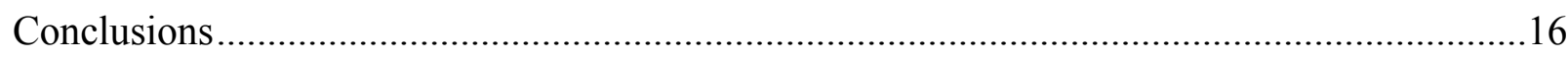

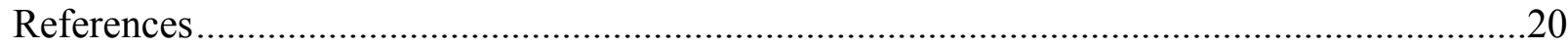




\section{Abstract}

Magnetic modeling was performed to estimate achievable magnetic field strengths of superconducting undulators (SCUs) and to compare them with those of cryogenically cooled permanent magnet undulators (CPMUs). Starting with vacuum (beam stay-clear) gaps of 4.0 and $6.0 \mathrm{~mm}$, realistic allowances for beam chambers (in the SCU case) and beam liners (in the CPMU case) were added. (A 6.0-mm vacuum gap is planned for the upgraded APS). The CPMU magnetic models consider both CPMUs that use NdFeB magnets at $\sim 150 \mathrm{~K}$ and PrFeB magnets at $77 \mathrm{~K}$. Parameters of the magnetic models are presented along with fitted coefficients of a Halbach-type expression for the field dependence on the gap-to-period ratio. Field strengths for SCUs are estimated using a scaling law for planar SCUs; an equation for that is given. The SCUs provide higher magnetic fields than the highest-field CPMUs - those using PrFeB at $77 \mathrm{~K}$ - for period lengths longer than $\sim 14 \mathrm{~mm}$ for NbTi-based SCUs and $\sim 10 \mathrm{~mm}$ for $\mathrm{Nb}_{3} \mathrm{Sn}$-based SCUs. To show that the model calculations and scaling law results are realistic, they are compared to CPMUs that have been built and NbTi-based SCUs that have been built. Brightness tuning curves of CPMUs (PrFeB) and SCUs (NbTi) for the upgraded APS lattice are also provided for realistic period lengths.

\section{Introduction}

Cryogenic permanent magnet undulators (CPMUs) are the extension to lower temperatures of the well-established in-vacuum undulators. At cryogenic temperatures, permanent magnets produce higher magnetic field and are more radiation-resistant than at room temperature, advantages that make CPMUs appealing and, as a result, increasingly common worldwide $[1,2,3]$. Comparisons of future undulator technologies for use in storage rings and free electron lasers have been extensively reported in the literature - for good overviews see papers by Bahrdt [4], Couprie [5], and Chavanne [6].

At the Advanced Photon Source (APS), superconducting technology was chosen as a means of achieving enhanced undulator capabilities. The first superconducting undulator (SCU), called SCU0, to be installed in the APS storage ring was successfully commissioned in January 2013 [7]. As technology development proceeded, the SCU0 was followed by the SCU18\#1 and the SCU18\#2, both 18-mm-period undulators with a magnetic length of $1.1 \mathrm{~m}$, in 2015 and 2016, respectively [8]. The SCU0 was replaced by the longer SCU18\#2 after 3.5 years of continuous successful operation in the storage ring.

The various undulator technologies have different advantages, but one of the most important aspects of an undulator is the strength of the magnetic field as a function of undulator gap and period length. Insertion devices (IDs) with short period lengths offer increased brightness and flux, but come with the trade-off of a reduced magnetic field strength. A high magnetic field strength provides extended harmonic energy tuning ranges. Here we focus on the comparison of computed magnetic field strengths achievable over a range of period lengths with both technologies under realistic conditions and on comparing those strengths with measured values. This study covers primarily SCUs fabricated with NbTi superconducting wires since all 
undulators installed in storage rings to date use this material. It is important to note, however, that successful construction and stable operation of $\mathrm{Nb}_{3} \mathrm{Sn}$-based SCUs in storage rings will offer the possibility of much higher magnetic fields for the same period length. (Work has begun in this direction but no experimental results or fabrication challenges are reported on in this study.)

The interest in cryogenic permanent magnet materials comes from the increase in remanent field and coercivity of the permanent magnets at low temperatures, providing both higher magnetic field and higher resistance to radiation-induced demagnetization of the magnet compared to room-temperature operation. The newer grades of PrFeB show higher performance than the grades of $\mathrm{NdFeB}$ because, unlike $\mathrm{NdFeB}$, there is no spin reorientation transition at $\sim 150 \mathrm{~K}$, so operation at colder temperatures becomes advantageous. (The spin reorientation reduces the on-axis undulator field if magnets are cooled below the transition temperature.) As a result, many recent undulators are constructed with PrFeB magnets [9]. This study presents results for both magnet materials. Further, a comprehensive literature review was undertaken with key results summarized in tables for quick access at the end.

\section{Magnetic Computer Models}

Calculations were carried out using the OPERA-3D code [10] to estimate the field strength achievable with a cryogenic permanent magnet undulator. Models using both PrFeB and $\mathrm{NdFeB}$ magnets were explored for a hybrid configuration, with vanadium permendur poles between the magnets. Choices made in the design were aimed at making the field of the CPMU large without being inconsistent with the range of fabricated undulators. One example of such a choice is selecting strong magnet grades.

The magnetic parameters used for PrFeB were those of grade NMX-68CU from the Neomax Engineering subsidiary of Hitachi Metals, which is being used at the Taiwan Photon Source (TPS) [11]. For NdFeB, the magnetic parameters used were those of grade NMX-S45SH, also from Neomax. This is the grade chosen for the CPMU at the Swiss Light Source (SLS) [12]. Both of these grades are either the strongest or very close to the strongest grades used in existing CPMUs. The important magnetic characteristics are summarized in Table 1.

Table 1. Magnetic characteristics of the $\mathrm{NdFeB}$ and PrFeB magnet grades used in the computer models. Note that cryogenic $\mathrm{NdFeB}$ operation was set at a temperature of $\sim 150 \mathrm{~K}$ to avoid the reduction in $\mathrm{B}_{\mathrm{r}}$ due to spin reorientation at lower temperatures.

\begin{tabular}{|l|l|c|c|c|c|c|}
\hline Material & Temp & $\mathrm{B}_{\mathrm{r}}(\mathrm{T})$ & $\mathrm{H}_{\mathrm{cB}}(\mathrm{kA} / \mathrm{m})$ & $\mathrm{H}_{\mathrm{cB}}(\mathrm{Oe})$ & $\mathrm{H}_{\mathrm{cJ}}(\mathrm{kA} / \mathrm{m})$ & $\mathrm{H}_{\mathrm{cJ}}(\mathrm{Oe})$ \\
\hline PrFeB NMX-68CU & $77 \mathrm{~K}$ & 1.67 & 1240 & 15582 & 6200 & 77911 \\
\hline PrFeB NMX-68CU & $295 \mathrm{~K}$ & 1.40 & 1010 & 12692 & 1680 & 21112 \\
\hline NdFeB NMX-S45SH & $150 \mathrm{~K}$ & 1.50 & 1137 & 14288 & 4000 & 50265 \\
\hline NdFeB NMX-S45SH & $293 \mathrm{~K}$ & 1.30 & 970 & 12200 & 1671 & 21000 \\
\hline
\end{tabular}


The vanadium permendur B-H curve used for the pole material was the same as that used for the room-temperature undulator field calculations at APS. It gives good agreement with the finished APS devices. No changes have been made to adapt it for cryogenic temperatures, but it is expected to be a good approximation. Data on temperature dependence received from Vacuumschmelze shows a very small difference (less than $1 \%$ ) in $\mu_{\mathrm{r}}$ between $80{ }^{\circ} \mathrm{C}$ and $-30{ }^{\circ} \mathrm{C}$ (minimum listed temperature) for $\mathrm{H}$ above about $3 \mathrm{Oe}$. (A temperature of $150 \mathrm{~K}$ is about as far from room temperature as $-30^{\circ} \mathrm{C}$ is from $80{ }^{\circ} \mathrm{C}$, so to the extent that the magnetic response can be extrapolated to $\sim 150 \mathrm{~K}$, the established numbers for $\mu_{\mathrm{r}}$ at room temperature are expected to be reasonably good.)

\section{Results}

\section{Computed Magnetic Fields of Cryogenic Permanent Magnet Undulators (CPMUs)}

The magnetic designs are intended to be realistic with the emphasis on building an undulator with a strong magnetic field. Other considerations, such as not demagnetizing the magnets during assembly or bakeout (in case a bakeout procedure is required), or minimizing the overall height of the parts of the undulator that need to fit into a vacuum chamber, may lead to other design choices. Dimensions used for the magnets and poles, such as the pole and magnet widths and the magnet overhang on the back of the poles, are similar to those used for conventional short-period undulators at the APS. Further optimization of most of the dimensions would not have a strong impact on the on-axis effective or peak magnetic fields. Those dimensions that would have a larger impact on achieving the highest undulator field, i.e., the thicknesses (in the beam direction) of the magnet and pole, have been optimized for each design. The overall dimensions of magnets and poles and results of design optimizations are summarized in Table 2 for 4 different period lengths $(0.8,1.1,1.5$, and $2.0 \mathrm{~cm})$.

Table 2. Summary of parameters for models and results for two magnetic gaps: $0.42 \mathrm{~cm}$ and $0.62 \mathrm{~cm}$. Optimizations were performed at $0.42 \mathrm{~cm}$ gap. $\mathrm{H}_{\mathrm{zworst}}$ is the worst demagnetizing field seen by the magnet. The coordinate system is defined such that $\mathrm{x}$ is in the transverse horizontal direction, $\mathrm{y}$ is in the vertical direction, and $\mathrm{z}$ is the longitudinal (beam) direction.

\begin{tabular}{|c|c|c|c|c|c|c|c|c|c|c|}
\hline \multirow[b]{2}{*}{ material } & \multirow[b]{2}{*}{$\begin{array}{l}\text { dimensions for all } \\
\text { models }\end{array}$} & \multicolumn{3}{|c|}{ ALL DIMENSIONS IN CM } & \multirow[b]{2}{*}{$\begin{array}{l}\text { Beff }(G) \text { at } \\
0.42 \mathrm{~cm} \text { gap }\end{array}$} & \multirow[b]{2}{*}{$\begin{array}{l}\text { Bpeak }(G) \text { at } \\
0.42 \mathrm{~cm} \text { gap }\end{array}$} & \multirow[b]{2}{*}{$\begin{array}{l}\text { Hzworst (Oe) } \\
0.42 \mathrm{~cm} \text { gap }\end{array}$} & \multirow[b]{2}{*}{$\begin{array}{l}\text { Beff }(G) \text { at } \\
0.62 \mathrm{~cm} \text { gap }\end{array}$} & \multirow[b]{2}{*}{$\begin{array}{l}\text { Bpeak (G) at } \\
0.62 \mathrm{~cm} \text { gap }\end{array}$} & \multirow[b]{2}{*}{$\begin{array}{l}\text { Hzworst (Oe) } \\
0.62 \mathrm{~cm} \text { gap }\end{array}$} \\
\hline & & period & magnet z & pole z & & & & & & \\
\hline PrFeB NMX-68CU 77K & & $\begin{array}{l}0.8 \\
\end{array}$ & 0.251 & 0.149 & 5823.7 & 5856.2 & 16582.6 & 2624.8 & 2631.9 & 16671.3 \\
\hline $\mathrm{Br}=16700 \mathrm{G}$ & magnet $x=6.4$ & 1.1 & 0.333 & 0.217 & 9347.9 & 9424.6 & 17725.9 & 5122.9 & 5138.4 & 17906.1 \\
\hline $\mathrm{Hcb}=15582 \mathrm{Oe}$ & magnet $y=5.0$ & 1.5 & 0.461 & 0.289 & 13071.2 & 13310.0 & 17805.0 & 8435.1 & 8499.1 & 18909.3 \\
\hline \multirow[t]{2}{*}{$\mathrm{Hcj}=77911 \mathrm{Oe}$} & pole $x=4.4$ & 2 & 0.535 & 0.465 & 16723.8 & 16520.8 & 18748.9 & 11448.2 & 11327.1 & 19934.9 \\
\hline & pole $y=4.2$ & & & & & & & & & \\
\hline NdFeB NMX-S45SH $150 \mathrm{~K}$ & all chamfers $=0.02$ & 0.8 & 0.262 & 0.138 & 5465.3 & 5505.5 & 15316.2 & 2459.3 & 2467.0 & 15355.6 \\
\hline $\mathrm{Br}=15000 \mathrm{G}$ & no magnet recess & 1.1 & 0.344 & 0.206 & 8809.0 & 8913.8 & 16622.6 & 4784.9 & 4805.6 & 16572.6 \\
\hline $\mathrm{Hcb}=14288 \mathrm{Oe}$ & & 1.5 & 0.438 & 0.312 & 12463.0 & 12561.2 & 17734.0 & 7643.8 & 7662.5 & 17643.2 \\
\hline $\mathrm{Hcj}=50265 \mathrm{Oe}$ & & 2 & 0.546 & 0.454 & 15877.0 & 15771.9 & 18030.0 & 10642.4 & 10560.2 & 18613.5 \\
\hline
\end{tabular}


As can be seen in the table, the optimal magnet thickness varies with the choice of magnet material and period. For each case the optimization was performed at the minimum gap of 0.42 $\mathrm{cm}$. The column labeled ' $\mathrm{H}_{\mathrm{zworst}}$ ' is the worst demagnetizing field in the magnet at a gap of 0.42 $\mathrm{cm}$ or $0.62 \mathrm{~cm}$. (The demagnetizing field may be worse than this at another gap larger than 0.42 cm.)

A difference from the standard APS undulator designs is that the magnet tip is not recessed relative to the pole tip. (APS undulators typically have the pole tip extending $0.05 \mathrm{~cm}$ further towards the beam than the magnet tip; this provides space for placement of shims on the magnet tips without affecting the minimum gap. It reduces the on-axis field of the undulator, however.) Another difference from the standard APS undulator designs is that chamfers at the edges of the magnets and poles have been reduced to $0.02 \mathrm{~cm}$, i.e., just small enough to remove any sharp edges. In a more complete design intended for construction, some chamfering may be desired to help reduce the highest demagnetizing field in the magnets. For example, such a choice was made by Bahrdt et al. [13].

Note that space constraints inside a vacuum chamber, or other considerations, may restrict the height of the magnets and poles to smaller values than those used here, with some cost in magnetic field strength. The present choice of the magnet height of $5 \mathrm{~cm}$ is where the increase in field strength with height flattens, as shown in Fig. 1. As will be discussed in the section "Comparison of Generic CPMU Model Calculations to Real Undulators" the magnet heights chosen for the CPMUs that have been built (and for which magnet dimensions were published) are indeed shorter. The pole is assumed to be $0.8 \mathrm{~cm}$ shorter than the magnet; this is close to the values found in thoroughly optimized APS models with taller magnets, and it is also the value chosen for the CPMU at SOLEIL [9]. The difference in $\mathrm{B}_{\text {eff }}$ between a magnet height of $3 \mathrm{~cm}$ and $5 \mathrm{~cm}$ is about $1 \%$ (see Fig. 1). 


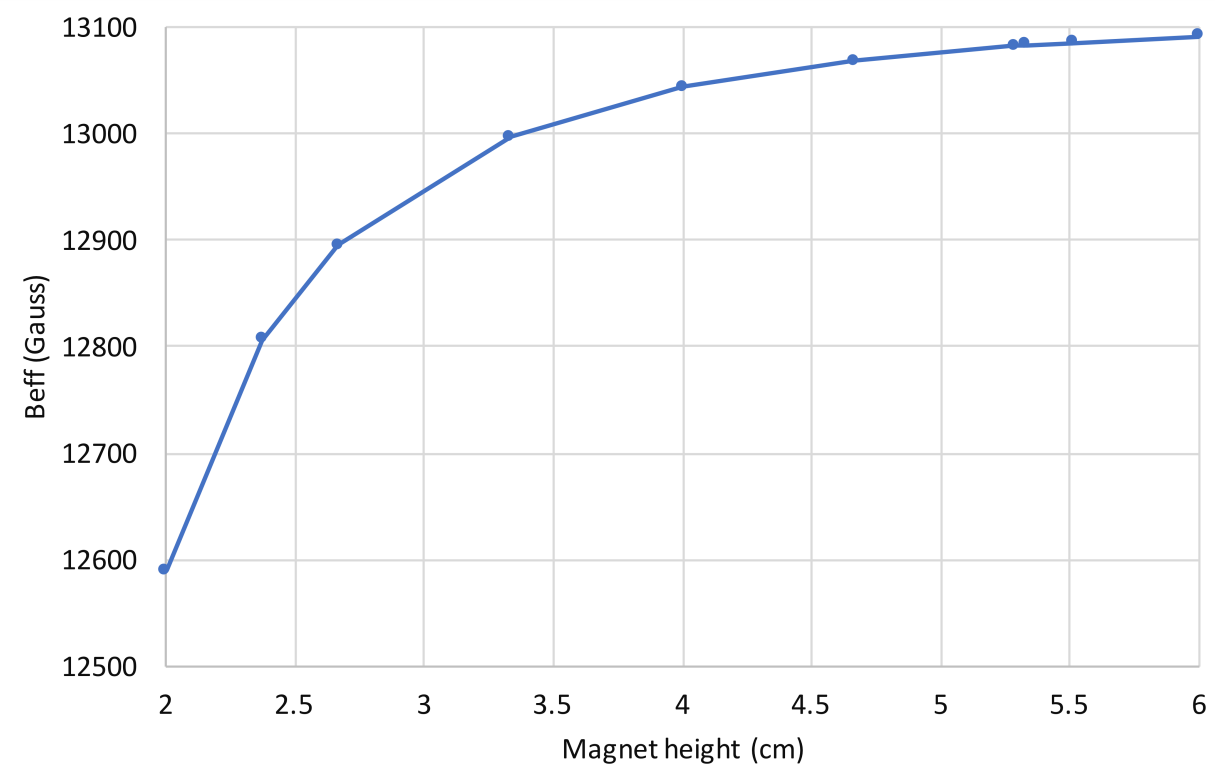

Fig. 1. Calculated effective magnetic field of the $1.5-\mathrm{cm}$-period undulator at the minimum gap of $0.42 \mathrm{~cm}$ for different values of the magnet height for the PrFeB magnet model. The pole is assumed to be $0.8 \mathrm{~cm}$ shorter than the magnet. A magnet height of $5.0 \mathrm{~cm}$ was chosen for the model computations.

An example of the optimization of the thickness of the magnet is shown in Fig. 2. The choice of magnet thickness also determines the pole thickness since the combined thickness is half of the period length.



Fig. 2. An example of the optimization of the magnet thickness (in the beam direction). The effective magnetic field for the $0.8-\mathrm{cm}$-period $\mathrm{PrFeB}$ model is shown at the minimum gap of $0.42 \mathrm{~cm}$. The orange line marks the chosen magnet thickness of $0.251 \mathrm{~cm}$. 
The optimized results for the peak and effective fields were further cross-checked using the code RADIA [14]. The Nd results agreed within $\sim 2 \%$. The Pr results varied a little more, but still agreed to better than $5 \%$.

\section{Comparison of Magnetic Fields of CPMUs, Superconducting Undulators (SCUs), and an In-} Vacuum SmCo Undulator (IVU)

The computed on-axis effective and peak magnetic fields of the modeled CPMUs (PrFeB and $\mathrm{NdFeB}$ ) optimized at $0.42 \mathrm{~cm}$ gap (see Table 2) were fitted to an equation of the form

$$
B_{f i t}=a * \exp \left(-b r+c r^{2}\right) \text {, }
$$

with unknown coefficients $a, b$, and $c$, where $r=$ magnetic gap/period. The fit is shown in Fig. 3 , and the derived coefficients for the different cases are given in Table 3 .

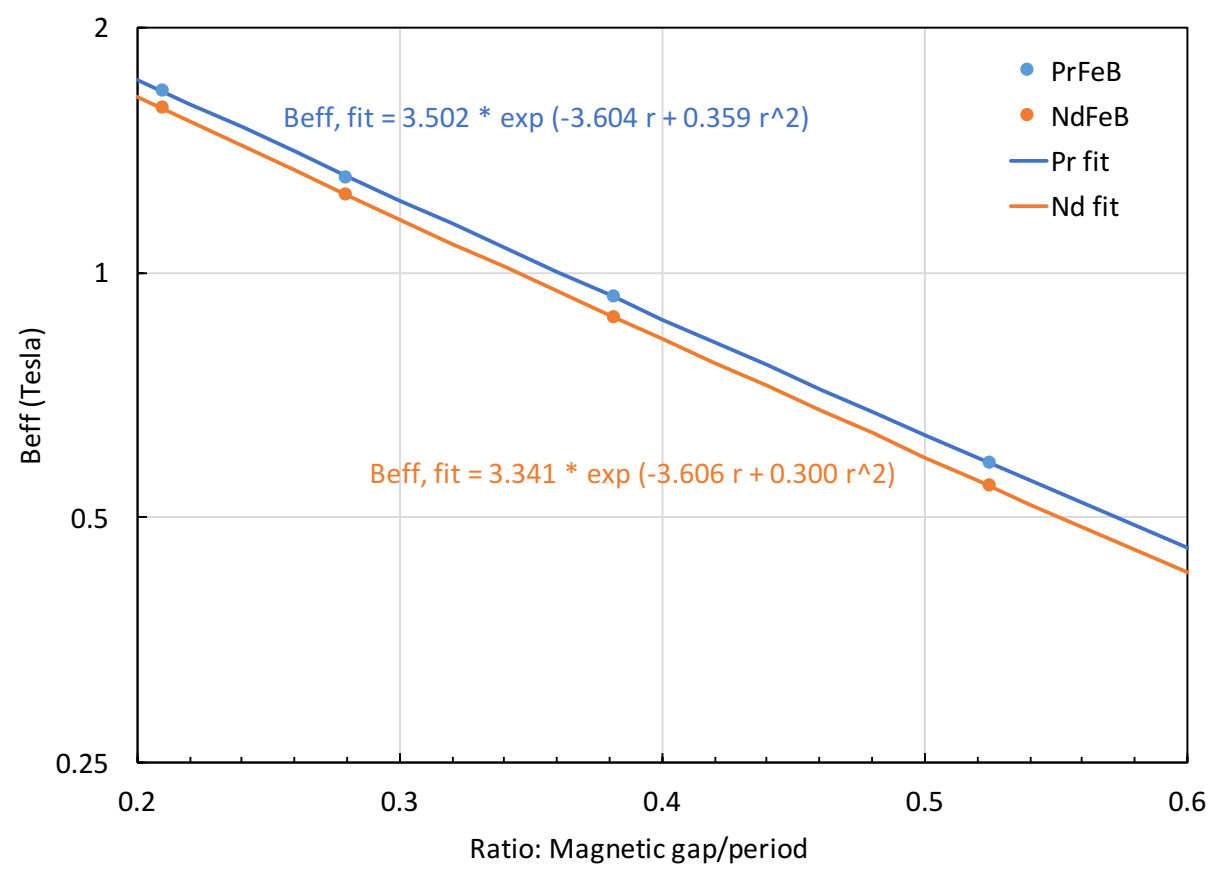

Fig. 3. Comparison of computer-modeled values of the effective magnetic fields for CPMUs based on $\mathrm{NdFeB}$ and PrFeB magnets, with fitted curves $\left(\mathrm{B}_{\text {eff }}\right.$ is from Table 2 for a magnetic gap of $4.2 \mathrm{~mm}$; coefficients used for $B_{\text {eff }}$ are from Table 3).

Table 3. Fitted coefficients of the effective and peak magnetic fields from model calculations to an expression of the form $B_{f i t}=a * \exp \left(-b r+c r^{2}\right)$. The two numbers given are for the effective field $\left(\mathrm{B}_{\text {eff,fit }}\right)$ and peak field $\left(\mathrm{B}_{\text {peak,fit }}\right)$, respectively.

\begin{tabular}{|l|c|c|c|c|c|}
\hline Magnet grade & Material & Temp. & $a_{\text {Beff }} / a_{B_{\text {peak }}}$ & $b_{B_{\text {eff }}} / b_{B_{\text {peak }}}$ & $c_{B_{\text {efff }}} / c_{B_{\text {peak }}}$ \\
\hline NMX-68CU & $\operatorname{Pr}_{2} \mathrm{Fe}_{14} \mathrm{~B}$ & $77 \mathrm{~K}$ & $3.502 / 3.198$ & $-3.604 /-3.062$ & $0.359 /-0.332$ \\
\hline NMX-S45SH & $\mathrm{Nd}_{2} \mathrm{Fe}_{14} \mathrm{~B}$ & $150 \mathrm{~K}$ & $3.341 / 3.121$ & $-3.606 /-3.204$ & $0.300 /-0.193$ \\
\hline
\end{tabular}


A similar parameterized fit was done previously for an in-vacuum SmCo undulator (IVU) assuming the use of Shin-Etsu's magnet grade R32HS, yielding the fit

$$
B_{e f f, f i t}=2.940 * \exp \left(-4.62 r+1.37 r^{2}\right)
$$

where $r$ is the ratio of magnetic gap/period [15].

For planar SCUs the scaling law [16] was used to calculate the magnetic fields of different period lengths $\lambda_{\mathrm{u}}$ and magnetic gaps $(\mathrm{g})$. For NbTi superconducting wires the parameterization at $80 \%$ of the critical current density $\mathrm{J}_{\mathrm{c}}$ is:

$$
\begin{gathered}
B_{o}=\left[0.28052+0.05798 \lambda_{u}(\mathrm{~mm})-0.0009 \lambda_{u}^{2}(\mathrm{~mm})+5 * 10^{-6} \lambda_{u}^{3}(\mathrm{~mm})\right] * \\
\exp \left[-\pi\left(\frac{g(\mathrm{~mm})}{\lambda_{u}(\mathrm{~mm})}-0.5\right)\right]
\end{gathered}
$$

where $\mathrm{g}$ is the magnetic gap of the SCU and $\lambda_{u}$ is its period.

For $\mathrm{Nb}_{3} \mathrm{Sn}$ superconducting wires the same expression was used but with the magnetic field enhanced by a multiplicative factor of 1.3. No distinction was made between the effective and peak magnetic fields but for all practical purposes they are considered the same because any differences are very small $(<1 \%)$.

Eq. 1 and the coefficients of Table 3 were used to compute, versus period length, the magnetic fields of CPMUs based on the two different magnet materials for two different vacuum gaps (beam stay-clear gaps): $4.0 \mathrm{~mm}$ and $6.0 \mathrm{~mm}$ (using magnetic gaps described below). The smallest vacuum gap of $4.0 \mathrm{~mm}$ represents a typical small-gap operation of a CPMU installed on a third-generation storage ring. The $6.0-\mathrm{mm}$ vacuum gap represents a gap feasible for the upgraded APS (APS-U).

The magnetic gap must be slightly larger than the vacuum gap. For the CPMUs there is a thin beam liner installed on top of the magnets and poles so that the beam sees a smooth surface for low impact on the beam impedance. The liner is typically made of a Ni-plated $\mathrm{Cu}$ foil with a thickness of $100 \mu \mathrm{m}$. A gap increase of $200 \mu \mathrm{m}$ allows for the top and bottom liners. For the SCUs, a thin-wall vacuum chamber with a wall thickness of $0.6 \mathrm{~mm}$ and an insulating gap of 0.3 $\mathrm{mm}$ adds up to a total gap allowance of $1.8 \mathrm{~mm}$, taking a vacuum gap of $6.0 \mathrm{~mm}$ to a magnetic gap of $7.8 \mathrm{~mm}$. While this allowance is $0.5 \mathrm{~mm}$ smaller than for the existing SCUs installed in the APS storage ring (where the vacuum gap is $7.2 \mathrm{~mm}$, the vacuum chamber wall thickness is $0.65 \mathrm{~mm}$ top and bottom, and the insulating gap is $0.5 \mathrm{~mm}$ top and bottom, making for a magnetic gap of $9.5 \mathrm{~mm}$ ), it uses the new $0.6-\mathrm{mm}$ thickness of the ID vacuum chambers being prototyped for the APS-U out-of-vacuum undulators. This 0.6-mm thickness will also be adopted for future SCUs at APS. At ANKA, a beam liner is used that allows for only a 1-mm difference between the vacuum and magnetic gaps [17].

As to the feasibility of installing IVUs in the APS-U storage ring with the new multi-bend achromat lattice, estimates for a vacuum gap of $\sim 6.0 \mathrm{~mm}$ show that there is not a significant impedance impact from an IVU. The relative impedance contributions from the ID transitions are markedly reduced in the new lattice as compared to the existing APS lattice. However, a lot of the particulars depend on the actual IVU transition designs, and to what extent the conducting foils placed on the magnets work as intended [18]. 
The calculated fields of the CPMUs are compared to the previously computed magnetic fields of a SmCo IVU and the $\mathrm{NbTi}$ and $\mathrm{Nb}_{3} \mathrm{Sn}$ SCUs in Figs. 4 (a) - (c) for a vacuum gap of 4.0 $\mathrm{mm}$ and in Figs. 5 (a) - (c) for a vacuum gap of $6.0 \mathrm{~mm}$.

As can be seen, the SCUs give the highest on-axis magnetic fields for period lengths longer than a certain threshold value. The exact value depends on details in the underlying assumptions. Here it occurs at $\sim 14 \mathrm{~mm}$ for $\mathrm{NbTi}$ and $\sim 10 \mathrm{~mm}$ for $\mathrm{Nb}_{3} \mathrm{Sn}$ (and essentially independent of the magnetic gaps chosen here). The threshold period length is probably smaller in reality because the SCUs here are assumed to operate at $80 \%$ of the critical current density but could in principle be operated at higher currents. Also, the parameters of the computed CPMU models were selected to give generous estimates of the CPMU fields. As discussed below, those estimates, when compared to CPMUs that have been built, are overestimates.

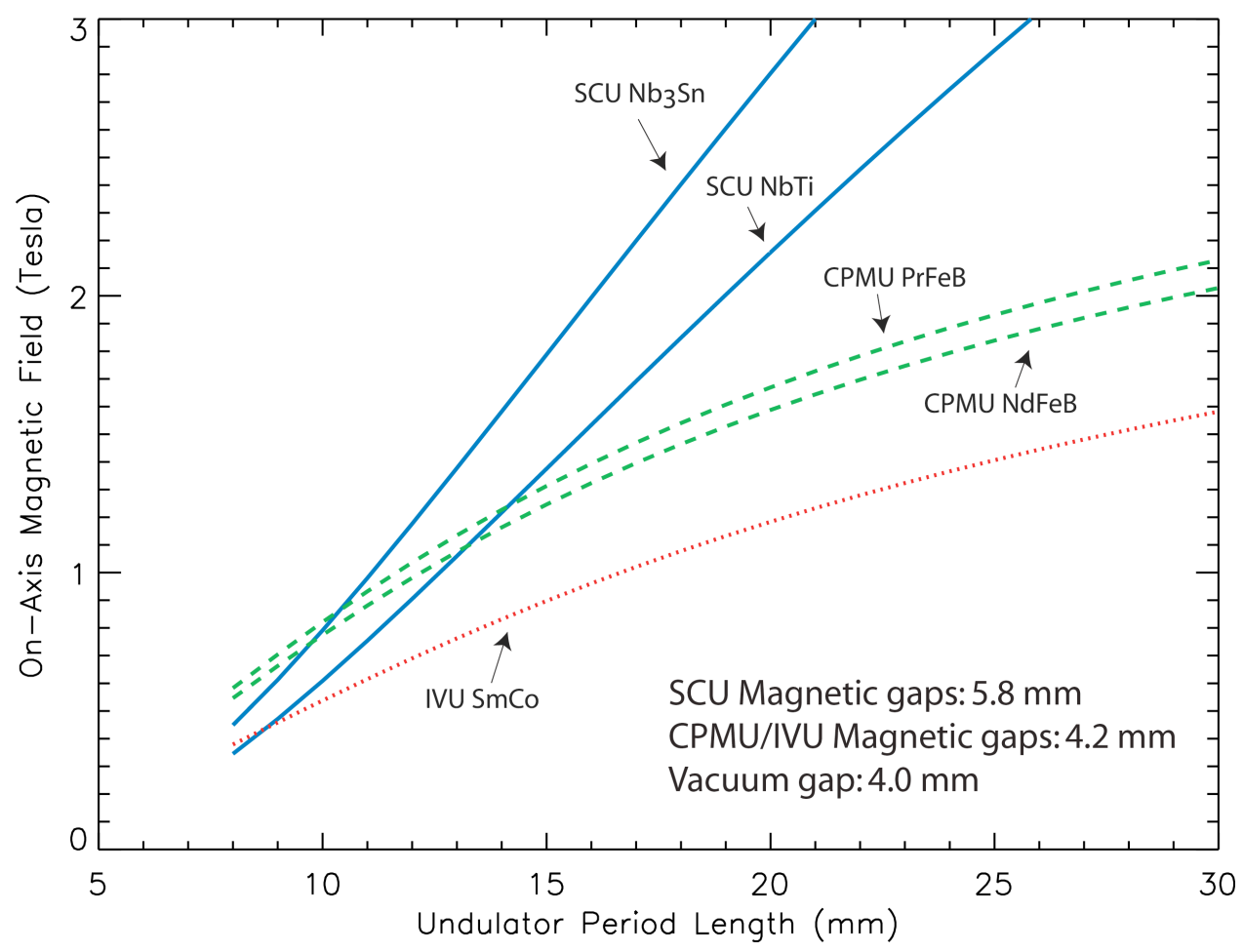

Fig. 4a. Calculated on-axis magnetic fields of two CPMUs (PrFeB, NdFeB), two SCUs ( $\mathrm{NbTi}, \mathrm{Nb}_{3} \mathrm{Sn}$ ), and one IVU (SmCo) for a vacuum gap of $4.0 \mathrm{~mm}$ for period lengths from $8 \mathrm{~mm}$ to $30 \mathrm{~mm}$. 


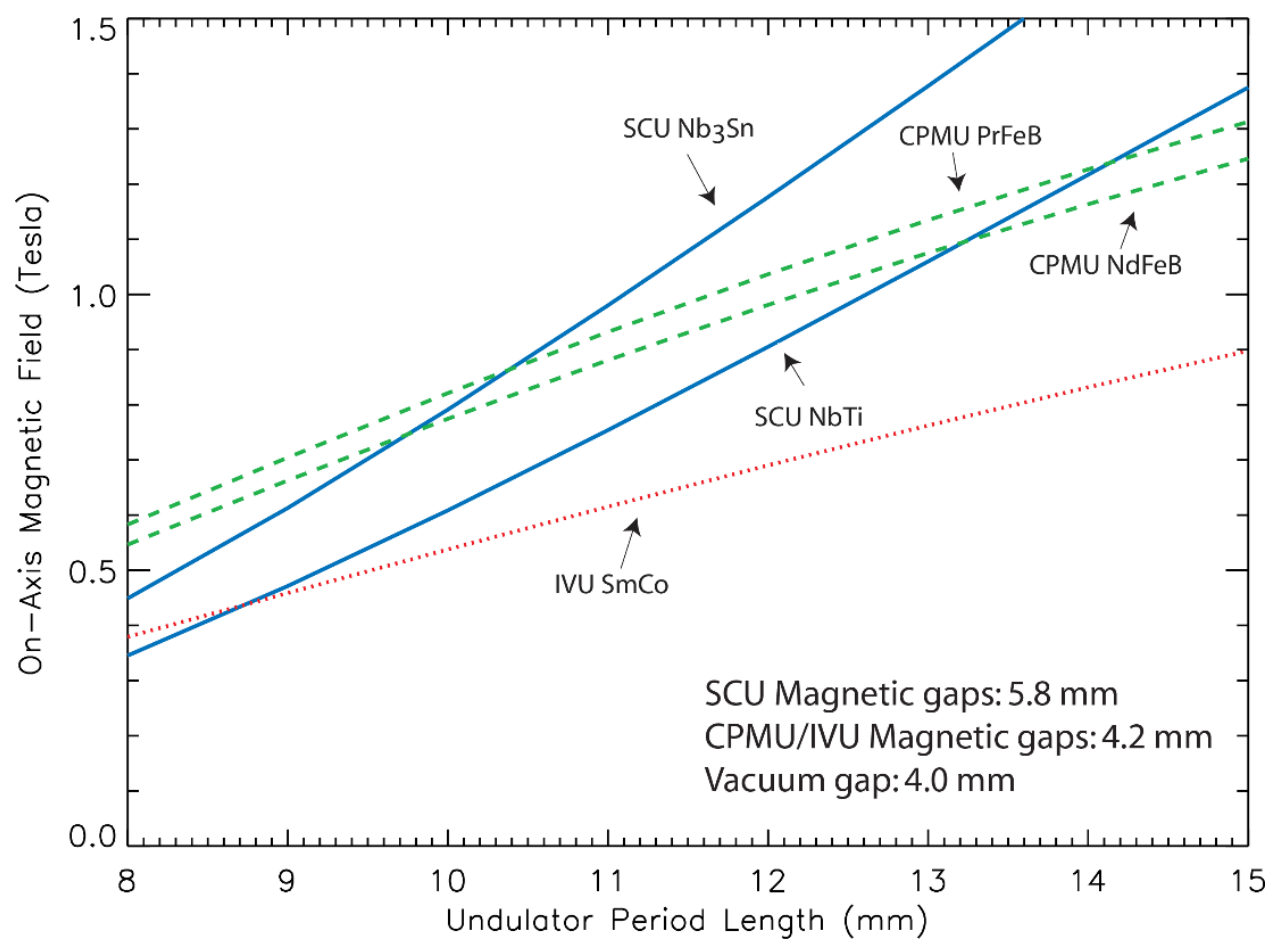

Fig. 4b. Close up view of the short-period region from Fig. 4a.

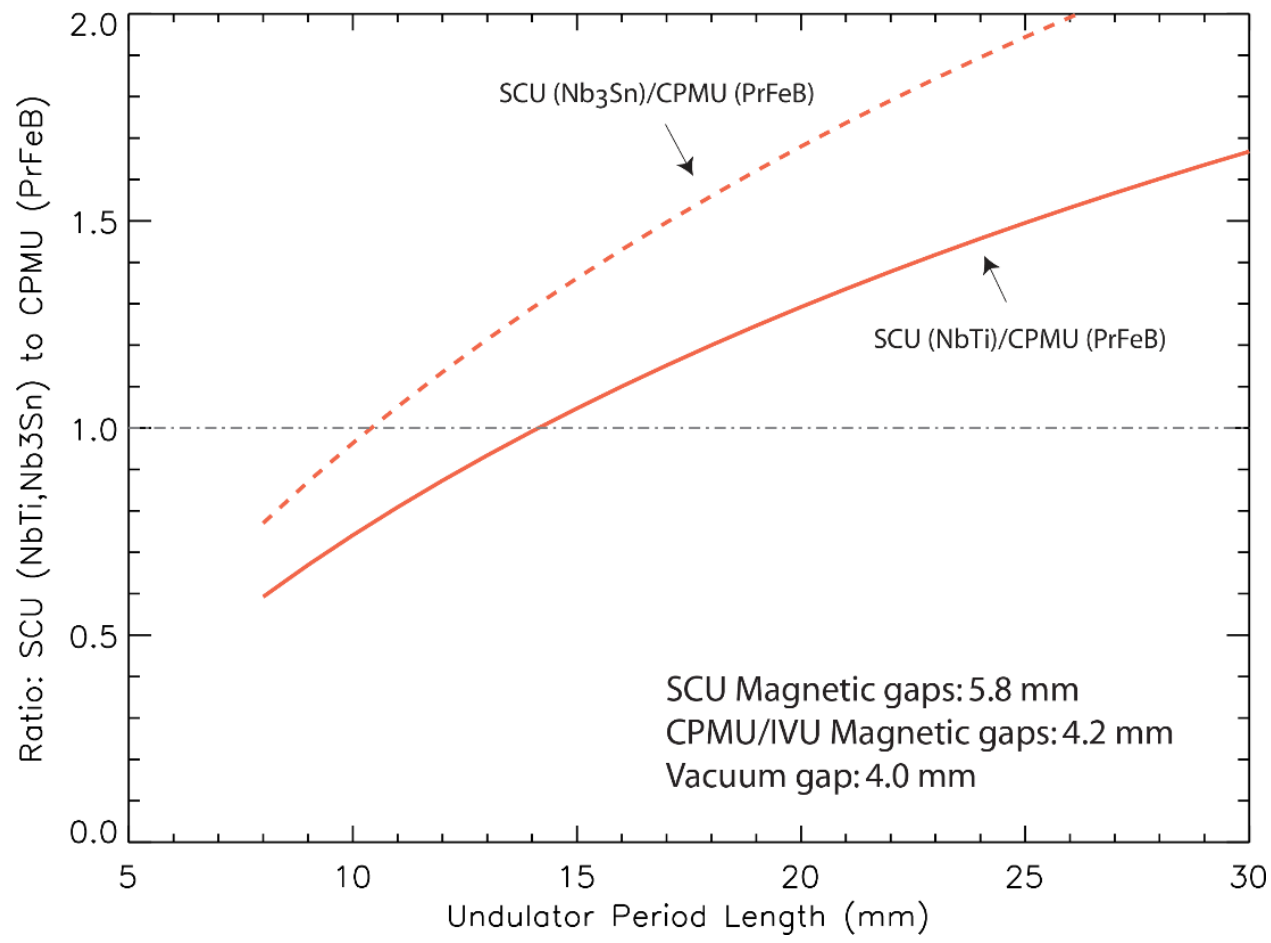

Fig. 4c. Ratio of the magnetic field of SCUs to that of PrFeB-based CPMUs; from data in Fig. 4a. 


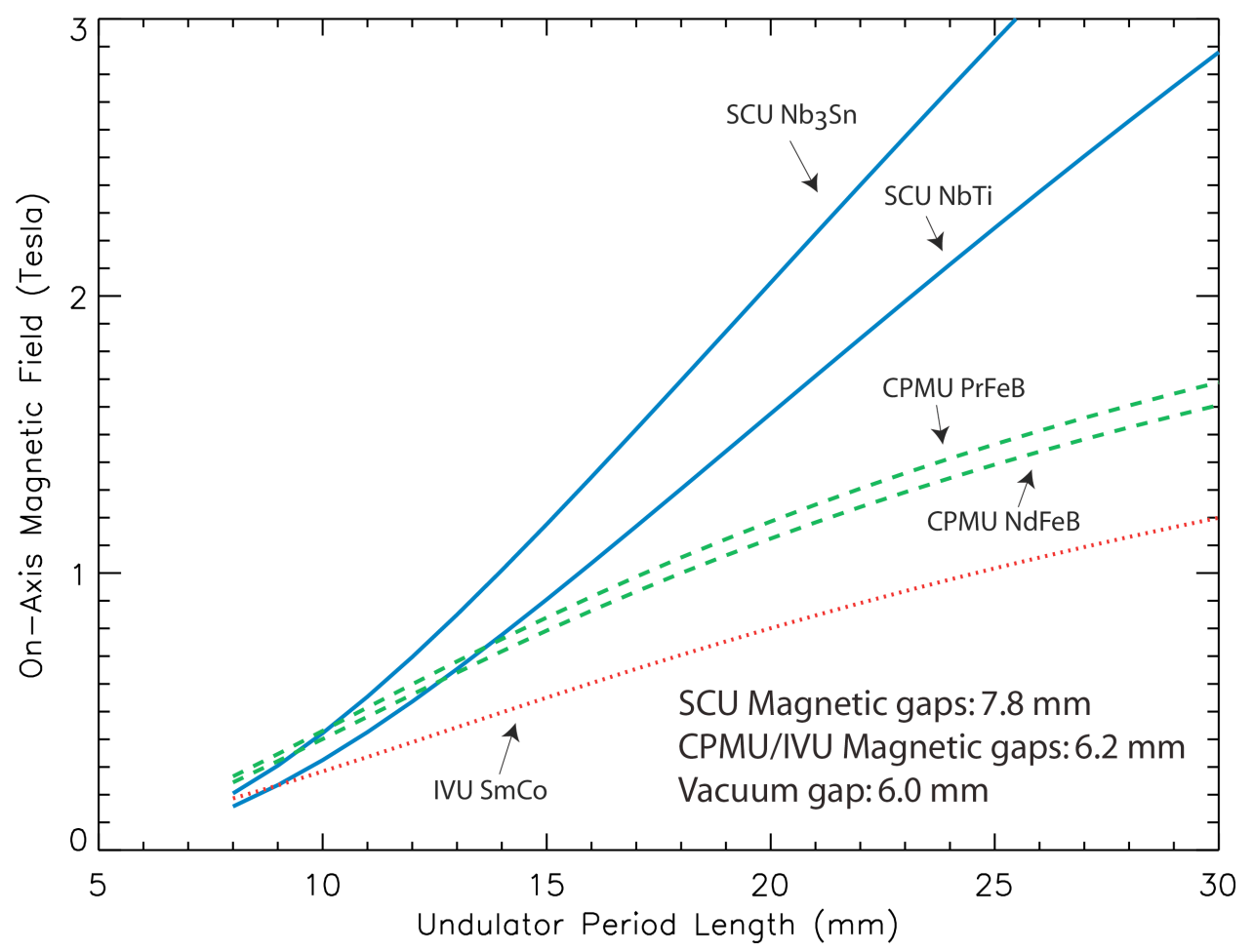

Fig. 5a. Calculated on-axis magnetic fields of two CPMUs (PrFeB, NdFeB), two SCUs ( $\mathrm{NbTi}, \mathrm{Nb}_{3} \mathrm{Sn}$ ), and one IVU (SmCo) for a vacuum gap of $6.0 \mathrm{~mm}$ for period lengths from $8 \mathrm{~mm}$ to $30 \mathrm{~mm}$. A 6-mm vacuum gap is feasible for the APS-U.

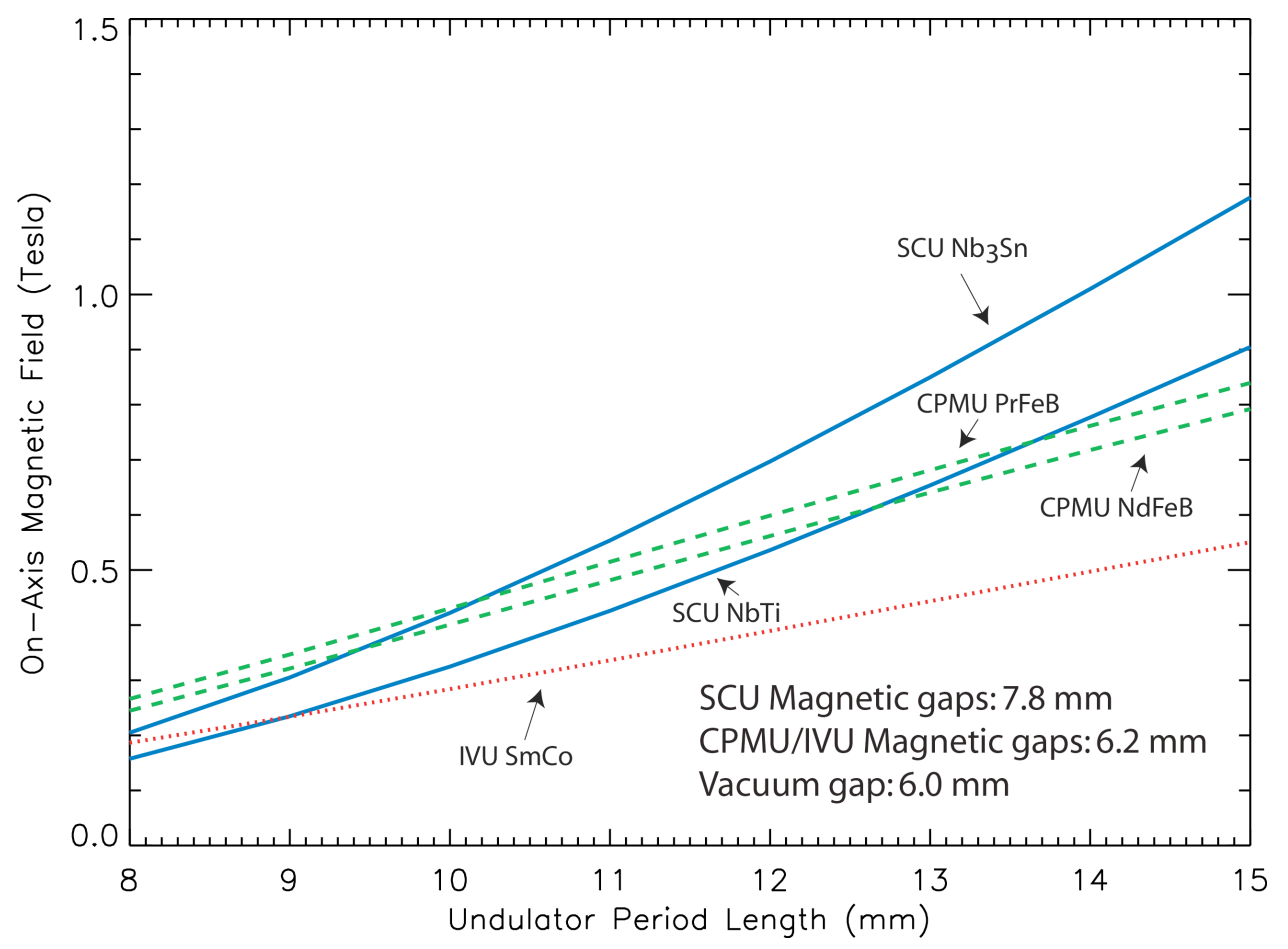

Fig. 5b. Close up view of the short-period region from Fig. 5a. 


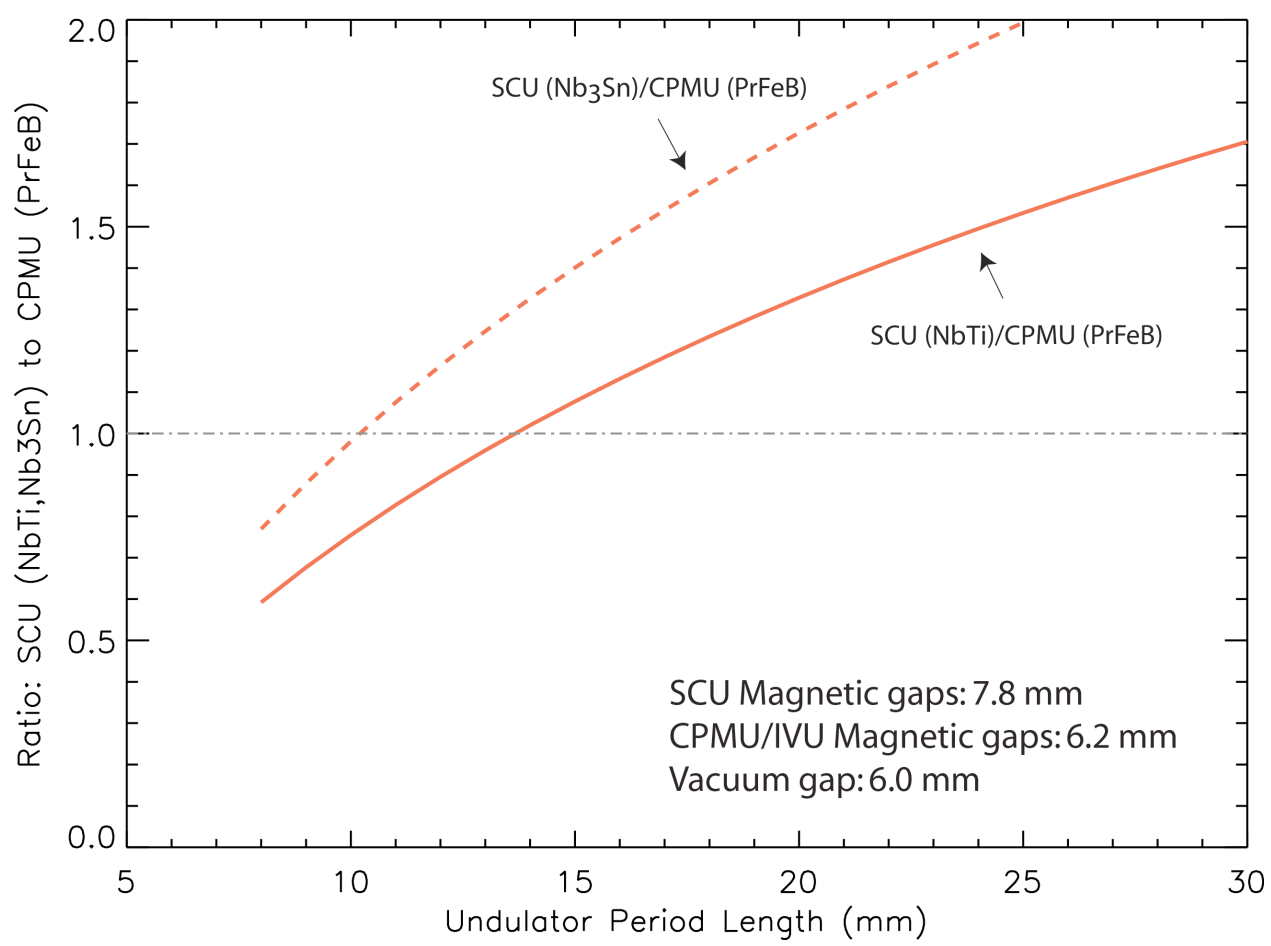

Fig. 5c. Ratio of the magnetic field of SCUs to that of PrFeB-based CPMUs; from data in Fig. 5a.

First Harmonic Energies and Brightness Tuning Curves for Undulators Installed on APS-U

A higher magnetic field for a given period length means that the energies of the harmonics will be lower. This is illustrated in Fig. 6, which shows the calculated first harmonic energies at $6 \mathrm{GeV}$ beam energy for a NbTi-based SCU and a PrFeB-based CPMU for period lengths $14-20$ $\mathrm{mm}$, which are important for the APS-U. A vacuum gap of $6.0 \mathrm{~mm}$ was assumed, which is realistic for the APS-U (the magnetic gaps are larger by the amounts discussed in the previous section). For example, a first harmonic energy of $11 \mathrm{keV}$ can be reached for period lengths of $15.5 \mathrm{~mm}$ and $16.0 \mathrm{~mm}$ for the SCUs (NbTi) and the CPMUs (PrFeB), respectively. 


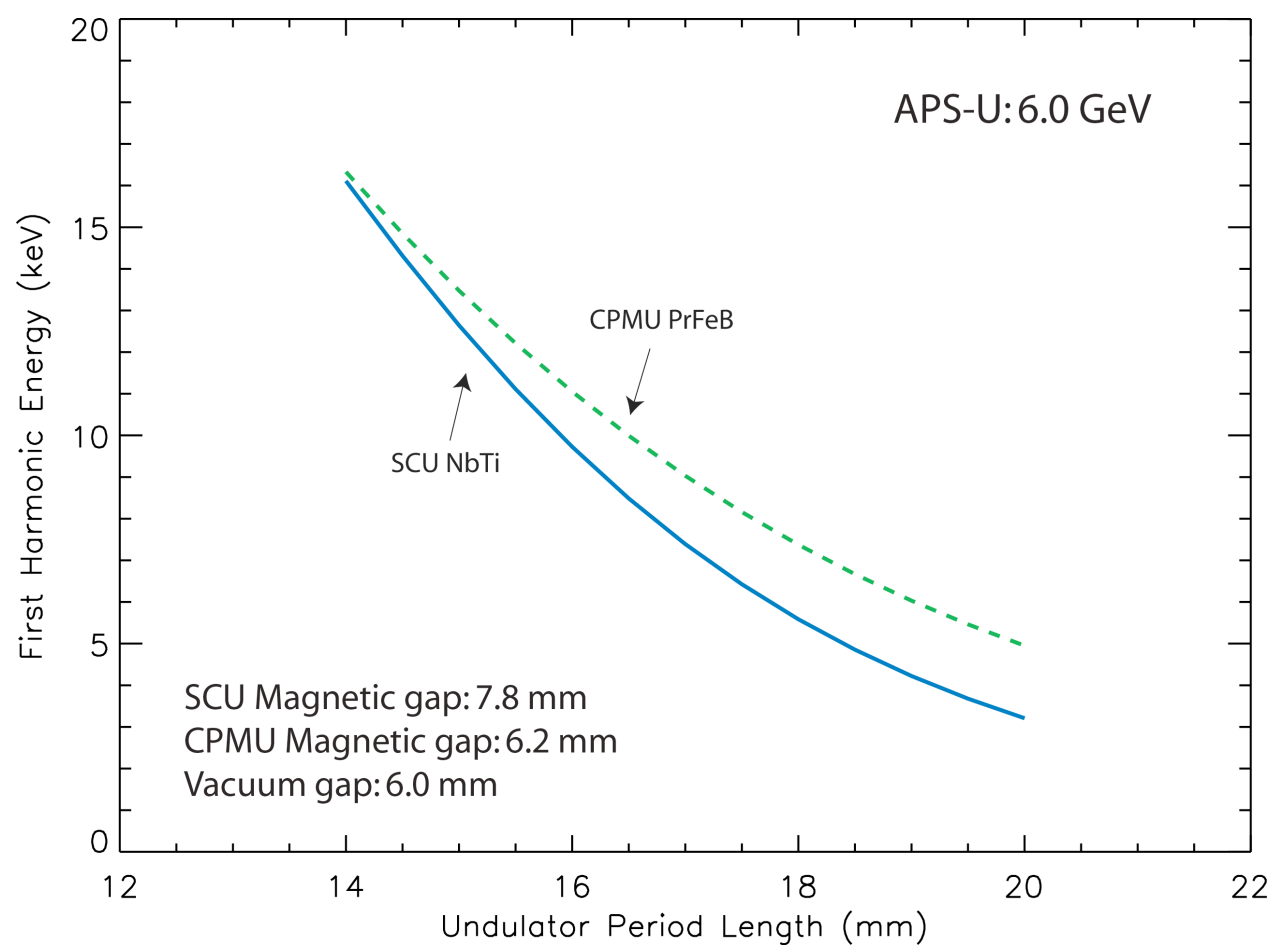

Fig. 6. Calculated first harmonic energies for SCUs (NbTi) and CPMUs (PrFeB) for a vacuum gap of 6.0 $\mathrm{mm}$ at $6 \mathrm{GeV}$ beam energy. The SCUs are assumed to be operating at $80 \%$ of the critical current density.

The calculated brightness tuning curves of SCUs (NbTi) and CPMUs (PrFeB) with suitable period lengths for the APS-U are shown in Fig. 7. A CPMU with a period length of $2.0 \mathrm{~cm}$ is required for continuous energy coverage between the first and third harmonics (frequently a desired feature for the APS users). However, if an SCU with a $1.85-\mathrm{cm}$ period were chosen instead, both the lowest reachable first harmonic energy and the continuous energy coverage would be preserved with the added benefits of higher brightness and lower power. (An SCU with a $2.0-\mathrm{cm}$ period length would reach a lower first harmonic energy along with higher emitted power.)

In a similar way, a CPMU with a period length of $1.6 \mathrm{~cm}$ can be compared with either a 1.6$\mathrm{cm}$-period SCU or a $1.55-\mathrm{cm}$-period SCU. The $1.55-\mathrm{cm}$-period SCU would reach the same minimum first harmonic energy as the 1.6-cm-period CPMU, and have the same energy coverage range, but the brightness would be higher. Alternatively, the 1.6-cm-period SCU would provide the same brightness but the energy tunability range would extend to lower energy. This increased tunability range is especially pronounced in the higher harmonics. 


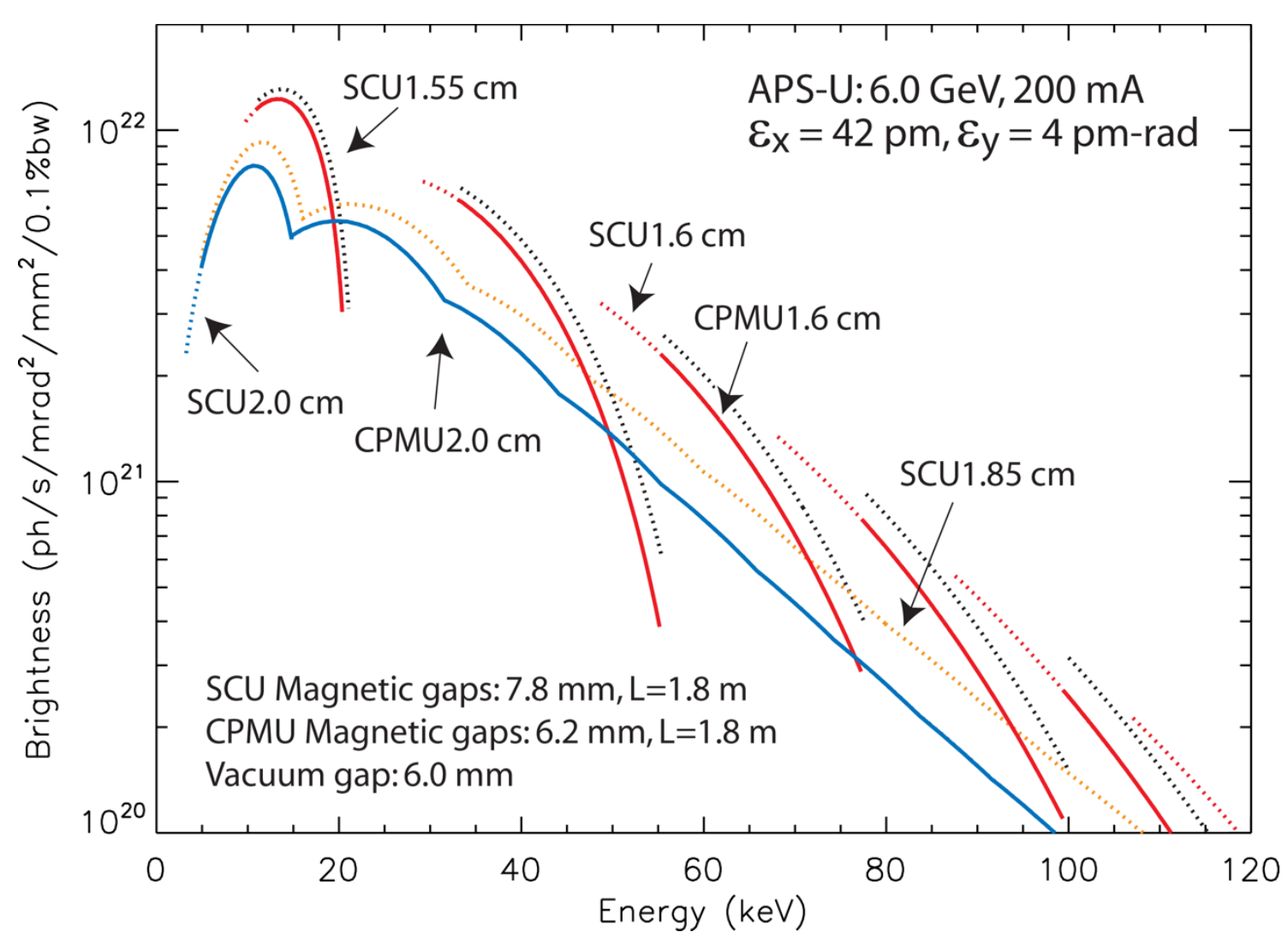

Fig. 7. Calculated brightness tuning curves of odd harmonics for CPMUs ( $\mathrm{PrFeB}$ - solid curves) and SCUs ( $\mathrm{NbTi}$ - dotted curves) for the APS-U 42-pm lattice for $6 \mathrm{GeV}$ beam energy and $200 \mathrm{~mA}$ beam current. Magnetic lengths of $1.8 \mathrm{~m}$ were assumed with no limitations due to high heat loads imposed. The SCU is assumed to be operating at $80 \%$ of the critical current density. The period lengths were chosen to show the tradeoff between a shorter period device that keeps the same tuning range and gives higher brightness vs. keeping the same period length so the brightness stays the same but the energy tuning range is wider, especially for the higher harmonics. Considerations of lowest energy required and whether gaps in the tuning range are acceptable help guide the choices. Estimated reductions of higher harmonics due to magnetic field errors were applied. 
Generic CPMU Model Calculations Compared to Real CPMUs

As stated above, the design decisions for the generic CPMU models were aimed at maximizing the magnetic field without straying very far from reality. To check the validity of the results, a comprehensive review of many of the existing and planned CPMUs worldwide was done. A summary of this is given in Tables 4 and 5 below, which show lists of real CPMUs, based on Nd or Pr magnets, respectively. Undulators that have been assembled and measured are included along with undulators in various stages of construction; the table states whether the values for the on-axis magnetic field are measured or computed for a particular magnetic design. There are separate columns for $\mathrm{B}_{\text {eff }}$ and $\mathrm{B}_{\text {peak }}$, but the difference is small as can be seen for the few CPMUs where values of both were reported in the literature. (The generic model calculation results shown in Table 2 above also showed only a small difference.)

The tables also include calculated values of $\mathrm{B}_{\text {eff }}$ computed from Eq. 1 using the coefficients listed in Table 3, and the ratio of those values to the measured values or the design values if measurements are not yet available. As can be seen, the computed magnet field is larger than the measured magnetic field in every case except for two undulators that are still in development (so that measurements are not yet available), though the overestimate is in many cases by only a few percent. Cases with larger discrepancies can be because the real undulator's magnetic design was not intended to produce an optimized field; instead the undulator was primarily developed to check some technical aspect of the CPMU design. Also, some undulators were constructed with weaker magnets than those assumed in the generic calculations - especially those where the magnets needed to survive a bakeout procedure. Overall the generic CPMU models give reasonable estimates of the field that an ideal CPMUs can provide. They do not, however, allow for schemes to enhance the field using additional magnets on the sides or backs of the poles [46] or for alternative pole materials such as Dy [47].

\section{SCU Scaling Law Compared to Real SCUs}

The scaling law expression given in Eq. 3 of the magnetic field of planar SCUs can also be compared to existing SCUs. Table 6 shows the characteristics of SCUs at the ANKA synchrotron radiation source in Karlsruhe, Germany and the APS, and of the LCLS R\&D SCU built at APS.

The scaling law assumes that the SCU is operating at $80 \%$ of the critical current. At the APS, the SCUs are operated close to $80 \%$ of the critical current (and sometimes higher) [7, 77], and the operating fields are within $\sim 1 \%$ of the scaling law predictions. Thus, the magnetic field calculated from the scaling law has been experimentally demonstrated at the APS for all 4 undulators built to date. The operating point given for the ANKA SCU15 device [71] is 60\%, so its operating field is correspondingly lower than the scaling law prediction. 


\section{Conclusions}

On-axis magnetic fields of planar CPMUs made of $\mathrm{NdFeB}$ and $\mathrm{PrFeB}$ permanent magnets and of SCUs made of $\mathrm{NbTi}$ and $\mathrm{Nb}_{3} \mathrm{Sn}$ superconducting wires were computed. The computations were based on magnetic design calculations of generic CPMU models and on the scaling law for the SCUs. The computed fields were compared to undulators that have been built to verify that the computed field strengths are realistic. For the CPMUs it was found that the computed magnet fields were larger than the measured fields in nearly every case. For the NbTibased SCUs that are operated at $80 \%$ of the critical current (as the APS undulators are), the measured magnetic fields were within $\sim 1 \%$ of predictions; the predictions assumed operation at $80 \%$.

From this we can conclude with high certainty that NbTi-based SCUs with period lengths longer than $\sim 14 \mathrm{~mm}$ and (although with less certainty) that $\mathrm{Nb}_{3} \mathrm{Sn}$-based SCUs with periods longer than $\sim 10 \mathrm{~mm}$ provide the highest magnetic fields for realistic magnetic gaps installed in storage rings. The higher magnetic fields give the choice of extending the brightness tuning ranges of harmonic energies (for the same period length) or shortening the period length to increase the photon brightness (for the same tuning ranges). The period lengths planned for APS-U are $16 \mathrm{~mm}$ or longer thus making the SCU the preferred choice. SCUs also offer the possibility of future significant improvements in undulator field strength once the promise of $\mathrm{Nb}_{3} \mathrm{Sn}$ conductors is realized. 
Table 4. List of CPMUs based on NdFeB magnets. In the column labeled 'Ratio Calc/Meas', the measured value is used when available, otherwise the design value is used.

\begin{tabular}{|c|c|c|c|c|c|c|c|c|c|c|c|c|c|c|c|c|c|c|}
\hline NdFeB & $\begin{array}{l}\text { Magnet Grade \& } \\
\text { Supplier }\end{array}$ & $\begin{array}{l}\text { Temp } \\
\text { (K) }\end{array}$ & $\mathrm{Br}(\mathrm{T})$ & $\begin{array}{c}\mathrm{Hcj} \\
(\mathrm{kOe})\end{array}$ & $\begin{array}{c}\text { Magn. } \\
\text { Gap } \\
(\mathrm{mm})\end{array}$ & $\begin{array}{r}\text { Period } \\
(\mathrm{mm})\end{array}$ & $\begin{array}{l}\text { No. of } \\
\text { Periods }\end{array}$ & $\begin{array}{l}\text { Overall } \\
\text { Length } \\
(\mathrm{m})\end{array}$ & $\begin{array}{c}B_{\text {peak }} \\
(T)\end{array}$ & $B_{\text {eff }}(T)$ & $\begin{array}{l}\text { Design or } \\
\text { Measured }\end{array}$ & $\begin{array}{l}\text { Magn. Dims: } \\
\mathrm{w} \times \mathrm{h} \times \mathrm{t} \\
(\mathrm{mm})\end{array}$ & $\begin{array}{c}\text { Pole Dims: } \\
w \times h \times t \\
(\mathrm{~mm})\end{array}$ & Status & $\begin{array}{l}\text { Gap / } \\
\text { Period }\end{array}$ & $\begin{array}{l}B_{\text {eff }} \text { Fit } \\
\text { (T) }\end{array}$ & \begin{tabular}{|l} 
Ratio \\
Calc/Meas
\end{tabular} & Reference(s) \\
\hline Diamond Light Source (DLS) & Vacodym 776 TP & $293 \mathrm{~K}$ & 1.31 & 21 & 4 & 17.7 & 113 & 2.05 & & 1.18 & meas. & & 33 wide & installed & 0.226 & & & {$[19,20]$} \\
\hline \multirow[t]{3}{*}{ (Built by Danfysik) } & VAC & $157 \mathrm{~K}$ & & & 4 & & & & & 1.263 & meas. & & & June 2010 & 0.226 & 1.502 & 1.19 & \\
\hline & & $293 \mathrm{~K}$ & & & 10 & & & & & 0.37 & meas. & & & & 0.565 & & & \\
\hline & & $157 \mathrm{~K}$ & & & 10 & & & & & 0.402 & meas. & & & & 0.565 & 0.479 & 1.19 & \\
\hline European Synchrotron Rad. Facility (ESRF) & Neorem 595t & $150 \mathrm{~K}$ & & & 6 & 18 & & 2 & 0.892 & & design & $50 \times 30 \times 6.2$ & $32 \times 24 \times 2.8$ & & 0.333 & 1.038 & 1.16 & [21 - 25] \\
\hline 1st CPMU; installed in ID6 test beamline & Neorem / VAC & $150 \mathrm{~K}$ & 1.28 & 54 & & & & & 0.881 & & meas. & & & installed & 0.333 & 1.038 & 1.18 & \\
\hline Note: Poles are of low-carbon steel & & $300 \mathrm{~K}$ & 1.17 & 27.6 & & & & & 0.821 & & meas. & & & $\operatorname{Jan} 2008$ & & & & \\
\hline European Synchrotron Radiation Facility & Vacodym 764 & $150 \mathrm{~K}$ & 1.5 & & 6 & 18 & & 2 & 0.99 & & meas. & & & installed & 0.333 & 1.038 & 1.05 & {$[26,27]$} \\
\hline 2nd CPMU; installed on ID11 & VAC & $293 \mathrm{~K}$ & 1.33 & 16 & & & & & 0.907 & & $\begin{array}{l}\text { meas. } \\
@ 297 \mathrm{~K}\end{array}$ & & & 2012 & & & & \\
\hline National Synchrotron Light Source (NSLS) & Neomax 42AH & $150 \mathrm{~K}$ & 1.45 & & 5.6 & 18 & 55 & 1.02 & 1.05 & & design & & & installed & 0.311 & 1.120 & 1.07 & {$[28,29]$} \\
\hline Cryo-ready MGU-X25 & Neomax / Hitachi & $293 \mathrm{~K}$ & 1.28 & 24 & & & & & 0.9 & & meas. & & & $\operatorname{Jan} 2006$ & & & & \\
\hline NSLS 10 -pole prototype & & $207 \mathrm{~K}$ & & & 4.75 & 13.5 & 3.5 & 0.15 & 0.95 & & meas. & & & & 0.352 & 0.975 & 1.03 & [28] \\
\hline NSLS PPM prototype & & $201.6 \mathrm{~K}$ & & & 6 & 16 & 18.5 & & 0.623 & & meas. & & & & 0.375 & 0.901 & 1.45 & {$[28]$} \\
\hline Shanghai Synchrotron Rad. Facility (SSRF) & $\mathrm{N} 48 \mathrm{H}$ & $138 \mathrm{~K}$ & 1.53 & 50 & 6 & 20 & 80 & & 1.06 & 1.03 & meas. & $65 \times 25 \times 6.2$ & $43 \times 20 \times 3.7$ & Feb 2015 & 0.300 & 1.164 & 1.13 & {$[30]$} \\
\hline Note: this $\mathrm{N} 48 \mathrm{H}$ has (Nd: $\mathrm{Pr}=3: 1$ ) & Zhejiang Innuovo & $300 \mathrm{~K}$ & 1.35 & 19.4 & & & & & 0.965 & 0.94 & meas. & & & & & & & \\
\hline \multirow[t]{3}{*}{ SOLEIL 4-period test. First test. } & Neomax 50BH & $293 \mathrm{~K}$ & 1.41 & 13.9 & 10 & 20 & 4 & & 0.5 & & meas. & $50 \times 30 \times 7.5$ & $33 \times 22 \times 2.5$ & & 0.500 & & & {$[31-35]$} \\
\hline & Neomax/Hitachi & $140 \mathrm{~K}$ & & 40 & & & & & 0.567 & & meas. & & & & 0.500 & 0.593 & 1.05 & \\
\hline & & $100 \mathrm{~K}$ & & 48 & & & & & 0.548 & & meas. & & & & 0.500 & & & \\
\hline SPring-8 CPMU prototype & Neomax 50BH & $130 \mathrm{~K}$ & 1.57 & & 5 & 15 & 40 & 0.6 & 0.92 & & meas. & & & & 0.333 & 1.038 & 1.13 & [2], [36 - 38] \\
\hline Pure permanent magnet design & Neomax / Hitachi & $300 \mathrm{~K}$ & 1.43 & & & & & & 0.805 & & meas. & & & & & & & \\
\hline \multirow[t]{2}{*}{ Spring-8 CPMU 15} & $\mathrm{NMX} 49 \mathrm{CH}$ & $300 \mathrm{~K}$ & 1.36 & 16 & & 15 & & 1.4 & & & & & & installed & & & & {$[39,40]$} \\
\hline & & $150 \mathrm{~K}$ & 1.48 & 38 & & & & & & & & & & Feb 2013 & & & & \\
\hline Swiss Light Source (SLS) CPMU14 & Neomax S45SH & $135 \mathrm{~K}$ & 1.5 & 50.3 & 4 & 14 & 120 & 1.7 & 1.15 & & meas. & & & 2010 & 0.286 & 1.222 & 1.06 & {$[12],[41-$} \\
\hline \multirow[t]{2}{*}{ collab. between SPring-8, Hitachi, PSI } & Neomax / Hitachi & $135 \mathrm{~K}$ & & & 3.5 & 14 & & & 1.3 & & meas. & & & & 0.250 & 1.382 & 1.06 & 43] \\
\hline & & $293 \mathrm{~K}$ & 1.3 & $\geq 21$ & & & & & & & & & & & & & & \\
\hline
\end{tabular}


Table 5. List of CPMUs based on magnets containing praseodymium ( $\mathrm{Pr}$ ). In the column labeled 'Ratio Calc/Meas', the measured value is used when available, otherwise the design value is used.

\begin{tabular}{|c|c|c|c|c|c|c|c|c|c|c|c|c|c|c|c|c|c|c|}
\hline PrFeB and $(\mathrm{Pr}, \mathrm{Nd}) \mathrm{FeB}$ & $\begin{array}{l}\text { Magnet Grade \& } \\
\text { Supplier }\end{array}$ & $\begin{array}{l}\text { Temp. } \\
\text { (K) }\end{array}$ & $\mathrm{Br}(\mathrm{T})$ & $\begin{array}{c}\mathrm{Hcj} \\
(\mathrm{KOe})\end{array}$ & $\begin{array}{l}\text { Magn. } \\
\text { Gap } \\
(\mathrm{mm})\end{array}$ & $\begin{array}{c}\text { Period } \\
(\mathrm{mm})\end{array}$ & $\begin{array}{c}\text { No. of } \\
\text { Periods }\end{array}$ & $\begin{array}{c}\text { Overall } \\
\text { Length } \\
(\mathrm{m})\end{array}$ & $\begin{array}{r}B_{\text {peak }} \\
(T)\end{array}$ & $B_{\text {eff }}(T)$ & \begin{tabular}{|c|} 
Design or \\
Measured
\end{tabular} & \begin{tabular}{|c|} 
Magnet \\
Dims: $\mathrm{w} x \mathrm{~h}$ \\
$\mathrm{xt}(\mathrm{mm})$
\end{tabular} & $\begin{array}{c}\text { Pole Dims.: } \\
\mathrm{w} \times \mathrm{h} \times \mathrm{t} \\
(\mathrm{mm})\end{array}$ & Status & $\begin{array}{l}\text { Gap / } \\
\text { Period }\end{array}$ & $\begin{array}{c}B_{\text {eff Fit }} \\
(T)\end{array}$ & $\begin{array}{c}\text { Ratio } \\
\text { Calc/Meas }\end{array}$ & Reference(s) \\
\hline \multicolumn{19}{|l|}{ Diamond Light Source (DLS) } \\
\hline European Synchrotron Radiation Facility (ESRF) & Vacodym 131 DTP & $80 \mathrm{~K}$ & $\geq 1.58$ & $>40$ & 5 & 14.4 & & 2 & 1 & & meas. & $38 \times 23 \times 4.7$ & $25 \times 18 \times 2.5$ & installed & 0.347 & 1.046 & 1.05 & [44- - 45] \\
\hline 3rd CPMU, installed on ID31. & PrFeB + GBD, VAC & $293 \mathrm{~K}$ & $\geq 1.38$ & $>20.6$ & & & & & & & & & & Jul 2016 & & & & \\
\hline Helmholtz-Zentrum Berlin (HZB) collab. with & $\left(\mathrm{Pr}_{8}, \mathrm{Nd}_{2 .}\right)_{2} \mathrm{Fe}_{14} \mathrm{~B}$ & $300 \mathrm{~K}$ & & & 2.5 & 9 & 20 & & 1.03 & 1.01 & design & $16 \times 14 \times 2.8$ & $12 \times 12 \times 1.6$ & $\sim 2011$ & 0.278 & & & {$[13],[46-49]$} \\
\hline Ludwig-Maximilian University München & VAC & $30 \mathrm{~K}$ & & & 2.5 & 9 & & & 1.15 & 1.12 & design & & & & 0.278 & 1.323 & 1.18 & \\
\hline Fixed-gap prototype for Max-Planck- & & $300 \mathrm{~K}$ & 1.42 & & 2.5 & & & & 0.996 & & meas. & & & & & & & \\
\hline Institut für Quantenoptik, Garching & & $25 \mathrm{~K}$ & 1.69 & & 2.5 & & & & 1.149 & & meas. & & & & 0.278 & 1.323 & 1.15 & \\
\hline \multirow[t]{2}{*}{ Used at Mainzer Microtron, MAMI } & & $300 \mathrm{~K}$ & & & 2 & 9 & & & & 1.28 & meas. & & & & 0.222 & & & \\
\hline & & $30 \mathrm{~K}$ & & & 2 & 9 & & & & 1.43 & meas. & & & & 0.222 & 1.600 & 1.12 & \\
\hline Helmholtz-Zentrum Berlin (HZB) & $(\mathrm{Pr}, \mathrm{Nd})_{2} \mathrm{Fe}_{14} \mathrm{~B}$ with & $293 \mathrm{~K}$ & 1.38 & 20.6 & 2.5 & 9 & 11 & & 1 & & meas. & & $14 \times 14 \times 2.44$ & & 0.278 & & & {$[49,50]$} \\
\hline Prototype with side magnets integrated & GBD. VAC & $77 \mathrm{~K}$ & 1.62 & 67.1 & & & & & & & & & in total & & & & & \\
\hline into the poles & & $20 \mathrm{~K}$ & & & & & & & 1.25 & & meas. & & & & 0.278 & 1.323 & 1.06 & \\
\hline HZB CPMU15 under development for FEL & $\begin{array}{l}{\left[\left(\mathrm{Pr}_{.8}, \mathrm{Nd}_{22}\right)_{2} \mathrm{Fe}_{14} \mathrm{~B}\right]} \\
\text { with GBD. VAC } \\
\end{array}$ & & & & 2 & 15 & 130 & 2 & & 2.14 & design & & & in dev. & 0.133 & 2.180 & 1.02 & [49], [51] \\
\hline \multirow[t]{2}{*}{ HZB CPMU17 under development for BESSY } & {$\left[\left(\mathrm{Pr}_{8}, \mathrm{Nd}_{2}\right)_{2} \mathrm{Fe}_{14} \mathrm{~B}\right]$} & $300 \mathrm{~K}$ & $>1.38$ & $>20.6$ & 5.5 & 17 & 87.5 & 1.6 & & & in dev. & & & & & & & [49], [52 - 53] \\
\hline & with GBD. VAC & $77 \mathrm{~K}$ & $>1.62$ & $>67.1$ & & & & & & 1.17 & design & & & in dev. & 0.324 & 1.133 & 0.97 & \\
\hline IHEP & PrFeB with GBD & $<85 \mathrm{~K}$ & 1.58 & 77.9 & 5 & 13.5 & 140 & 2 & 1 & & design & 4.5 thick & 2.25 thick & in dev. & 0.370 & 0.968 & 0.97 & {$[54-57]$} \\
\hline \multirow[t]{2}{*}{ NSLS short prototype } & NMX 53CR (PrFeB) & $77 \mathrm{~K}$ & & & 4.85 & 14.5 & 8 & & 0.9 & & meas. & & & & 0.334 & 1.092 & 1.21 & [58] \\
\hline & Neomax & $300 \mathrm{~K}$ & & & & & & & 0.75 & & & & & & & & & \\
\hline \multirow[t]{2}{*}{ NSLS bakeable prototype } & NMX-47CR $\left(\mathrm{Pr}_{2} \mathrm{Fe}_{14} \mathrm{~B}\right.$ & $300 \mathrm{~K}$ & 1.21 & 30 & 5 & 16.8 & 9.5 & & 0.92 & & meas. & $50 \times 29 \times 5.6$ & $40 \times 25.5 \times 2.8$ & & 0.298 & & & [59- 60] \\
\hline & Neomax & $77 \mathrm{~K}$ & & & & & & & 1.049 & & meas. & & & & 0.298 & 1.237 & 1.18 & \\
\hline \multirow[t]{2}{*}{ SOLEIL 4-period test. 2nd test. } & NMX-53CR $\left(\mathrm{Pr}_{2} \mathrm{Fe}_{14} \mathrm{~B}\right.$ & $293 \mathrm{~K}$ & 1.35 & 16.5 & 10 & 18 & 4 & & 0.367 & & meas. & $50 \times 30 \times 6.5$ & $33 \times 22 \times 2.5$ & & 0.556 & & & [33-35] \\
\hline & Neomax & $77 \mathrm{~K}$ & 1.57 & & & & & & 0.435 & & meas. & & & & 0.556 & 0.528 & 1.21 & \\
\hline SOLEIL First full PrFeB/VP undulator & NMX-53CR $\left(\mathrm{Pr}_{2} \mathrm{Fe}_{14} \mathrm{~B}\right.$ & $293 \mathrm{~K}$ & 1.35 & 16.3 & 5.5 & 18 & 107 & & 1.04 & & meas. & $50 \times 30 \times 6.5$ & $33 \times 22 \times 2.5$ & installed & 0.306 & 1.204 & & {$[33,34],[61-65]$} \\
\hline for NANOSCOPIUM beamline & Neomax & $77 \mathrm{~K}$ & 1.57 & 76 & & & & & 1.152 & & meas. & & & Aug 2011 & 0.306 & 1.204 & 1.05 & \\
\hline $\begin{array}{l}\text { SOLEIL U18n } 2 \text { cryo-ready und. for COXINEL } \\
\text { Installed; in use at room temp }\end{array}$ & & $293 \mathrm{~K}$ & 1.317 & 24 & 5 & 18 & & 2 & 1.156 & & & & & & & & & {$[62,63,65,66]$} \\
\hline SOLEIL U18n 3 for ANATOMIX beamline & & & & & & 18 & & 2 & & & in dev. & & & end 2017 & & & & {$[65,66]$} \\
\hline $\begin{array}{l}\text { SOLEIL U15 for PROXIMA II beamline, LUNEX5 } \\
\text { collab. With MAX-LAB }\end{array}$ & NMX-53CR $\left(\mathrm{Pr}_{2} \mathrm{Fe}_{14} \mathrm{~B}\right.$ & $77 \mathrm{~K}$ & & & 3 & 15 & 200 & 3 & 1.67 & & design & & & in dev. & 0.200 & 1.728 & 1.03 & {$[62,63,65-67]$} \\
\hline \multirow[t]{3}{*}{ Taiwan Photon Source TPS } & NMX-68CU $\left(\mathrm{Pr}_{2} \mathrm{Fe}_{14} \mathrm{~B}\right.$ & $77 \mathrm{~K}$ & 1.67 & 77.9 & 4 & 15 & 133 & 2 & 1.31 & 1.31 & design & $56 \times 20 \times 4.5$ & $46 \times 16 \times 3$ & in dev.; & 0.267 & 1.374 & 1.05 & {$[3],[68-70]$} \\
\hline & & $77 \mathrm{~K}$ & & & 3 & & & & & 1.71 & design & & & expected & 0.200 & 1.728 & 1.01 & \\
\hline & & $293 \mathrm{~K}$ & 1.4 & 21.1 & & & & & & & & & & June 2019 & & & & \\
\hline
\end{tabular}


Table 6. List of NbTi-based SCUs at ANKA [17, 71 - 74] and APS [7, 8, 75 - 77]. All but the ANKA SCU20 coils and the LCLS R\&D undulator have been operated with beam. The rightmost column gives the field strength calculated from Eq. 3, which uses the relevant magnetic gap and period and assumes operation at $80 \%$ of the critical current density.

\begin{tabular}{|c|c|c|c|c|c|c|c|c|c|c|c|}
\hline NbTi SCU & $\begin{array}{c}\text { Period } \\
(\mathrm{mm})\end{array}$ & $\begin{array}{l}\text { Gap } \\
(\mathrm{mm})\end{array}$ & $\begin{array}{l}\text { Magnetic } \\
\text { Gap }(\mathrm{mm})\end{array}$ & $B_{\text {peak }}(T)$ & $B_{\text {eff }}(T)$ & $\begin{array}{c}\text { Current } \\
\text { (A) }\end{array}$ & $\%$ of $I_{c}$ & $\begin{array}{l}\text { Magnetic } \\
\text { Length }(\mathrm{m})\end{array}$ & $\begin{array}{l}\text { No. of } \\
\text { Periods }\end{array}$ & $\begin{array}{c}\text { Magnetic } \\
\text { Gap/Period }\end{array}$ & $\begin{array}{l}\text { Fit for } \mathrm{NbTi} \\
\text { SCU @ 80\% }\end{array}$ \\
\hline ANKA SCUDEMO & 14 & 7 & 8 & 0.428 & & 650 & & & 100 & 0.571 & \\
\hline ANKA SCU15 & 15 & 7 & 8 & 0.73 & & 150 & 60 & & 100.5 & 0.533 & 0.8687 \\
\hline ANKA SCU20 coils & 20 & 7 & 8 & 1.187 & & 395 & & 1.5 & 75.5 & 0.400 & 1.5336 \\
\hline APS SCUO & 16 & 7.2 & 9.5 & 0.7351 & 0.7321 & 600 & 72 & 0.33 & 21 & 0.594 & 0.7436 \\
\hline APS SCU1 & 18 & 7.2 & 9.5 & 0.9625 & 0.9611 & 450 & 78 & 1.08 & 60 & 0.528 & 0.9730 \\
\hline APS SCU2 & 18 & 7.2 & 9.5 & 0.9635 & 0.9624 & 450 & 78 & 1.08 & 60 & 0.528 & 0.9730 \\
\hline LCLS R\&D undulator & 21 & 5.7 & 8 & 1.67 & & & & 1.5 & & 0.381 & 1.6679 \\
\hline
\end{tabular}




\section{References}

[1] T. Tanaka, Editor, "Recent Advancements of Undulator Technologies," Synchrotron Radiation News, May/June 2015, Vol. 28, No. 3.

[2] T. Hara, T. Tanaka, and H. Kitamura, "Cryogenic permanent undulators," Phys. Rev. Special Topics - Accelerator and Beams, 7, 050702 (2004).

[3] J.-C. Huang, Chin-Kang Yang, Cheng-Hsing Chang, Ting-Yi Chung, Yung-Teng Yu, Cheng-Hsiang Chang, Ching-Shiang Hwang, and Hideo Kitamura, "Challenge of in-vacuum and cryogenic undulator technologies," in Proceedings of IPAC 2016, Busan, Korea, (2016) 1080, TUZB02.

[4] J. Bahrdt and Y. Ivanyushenkov, "Short Period Undulators for Storage Rings and Free Electron Lasers," $11^{\text {th }}$ International Conference on Synchrotron Radiation Instrumentation (SRI 2012), Journal of Physics, Conf. Series 425 (2013) 032001.

[5] M.E. Couprie, "Undulator technologies for future free electron laser facilities and storage rings," in Proceedings of IPAC 2013, Shanghai, China, (2013) 26, MOZB102.

[6] J. Chavanne and G. LeBec, "Prospects for the use of permanent magnets in future accelerator facilities," in Proceedings of IPAC 2014, Dresden, Germany, (2014) 968, TUZB01.

[7] Y. Ivanyushenkov, K. Harkay, M. Abliz, L. Boon, M. Borland, D. Capatina, J. Collins, G. Decker, R. Dejus, J. Dooling, C. Doose, L. Emery, J. Fuerst, J. Gagliano, Q. Hasse, M. Jaski, M. Kasa, S. H. Kim, R. Kustom, J. C. Lang, J. Liu, E. Moog, D. Robinson, V. Sajaev, K. Schroeder, N. Sereno, Y. Shiroyanagi, D. Skiadopoulos, M. Smith, X. Sun, E. Trakhtenberg, I. Vasserman, A. Vella, A. Xiao, J. Xu, A. Zholents, E. Gluskin, V. Lev, N. Mezentsev, V. Syrovatin, V. Tsukanov, A. Makarov, J. Pfotenhauer, and D. Potratz, "Development and operating experience of a short-period superconducting undulator at the Advanced Photon Source," Phys. Rev. Special Topics - Accel. Beams, 18, 040703 (2015).

[8] Y. Ivanyushenkov, C. Doose, J. Fuerst, K. Harkay, Q. Hasse, M. Kasa, Y. Shiroyanagi, D. Skiadopoulos, E. Trakhtenberg, E. Gluskin, and P. Emma, "Status of the development of superconducting undulators for storage rings and free electron lasers at the Advanced Photon Source," in Proceedings of NAPAC 2016, Chicago, IL, USA, 1068, THA1CO06.

[9] C. Benabderrahmane, M. Valléau, A. Ghaith, P. Berteaud, L. Chapuis, F. Marteau, F. Briquez, O. Marcouillé, J.-L. Marlats, K. Tavakoli, A. Mary, D. Zerbib, A. Lestrade, M. Louvet, P. Brunelle, K. Medjoubi, C. Herbeaux, N. Béchu, P. Rommeluere, A. Somogyi, O. Chubar, C. Kitegi, and M.-E. Couprie, "Development and operation of a $\mathrm{Pr}_{2} \mathrm{Fe}_{14} \mathrm{~B}$ based cryogenic permanent undulator for a high spatial resolution x-ray beam line," Phys. Rev. Accel. Beams, 20, 033201 (2017).

[10] OPERA simulation software, http://www.cobham.com

[11] J.-C. Huang, H. Kitamura, C.-Y. Kuo, C.-K. Yang, C.-H. Chang, Y.-T. Yu, Y.-Y. Li, and C.-S. Hwang, "Design of a magnetic circuit for a cryogenic undulator in Taiwan photon Source," Proceedings of the $12^{\text {th }}$ International Conf. on Synch. Rad. Instrum. 2015, published in AIP Conf. Proc. 1741, 0200161; doi: 10.1063/1.4952795. 
[12] M. Calvi, Th. Schmidt, A. Anghel, A. Cervellino, S.J. Leake, P.R. Willmott, and T. Tanaka, "Commissioning Results of the U14 cryogenic undulator at SLS," Proceedings of the $11^{\text {th }}$ International Conf. on Synch. Rad. Instrum. 2012, published in Journal of Physics: Conf. Series 425 (2013) 032017 doi:10.1088/1742-6596/425/3/032017.

[13] J. Bahrdt, H.J. Bäcker, M. Dirsatt, W. Frentrup, A. Gaupp, D. Just, D. Pflückhahn, M. Scheer, B. Schulz, R. Weingartner, and F. Grüner, "Cryogenic Design of a PrFeB-based Undulator," in Proceedings of IPAC2010, Kyoto, Japan, 3111, WEPD012.

[14] RADIA simulation software, http://www.esrf.eu/Accelerators/Groups/InsertionDevices/Software/Radia

[15] R. Dejus, M. Jaski, and S.H. Kim, "On-Axis Brilliance of In-Vacuum Undulators for the Advanced Photon Source," ANL/APS/LS-314, 2009.

[16] S.H. Kim, “A scaling law for the magnetic fields of superconducting undulators," Nucl. Instrum. Methods A 546 (2005) $604-619$.

[17] S. Casalbuoni, A. Cecelia, S. Gerstl, N. Glaumann, A.W. Grau, T. Holubek, C. Meuter, D. Saez de Jauregui, R. Voutta, C. Boffo, Th. Gerhard, M. Turenne, and W. Walter "Characterization and long term operation of a novel superconducting undulator with $15 \mathrm{~mm}$ period length in a synchrotron light source," Phys. Rev. Accel Beams 19, (2016) 110702.

[18] R. Lindberg, APS, private communication.

[19] C.W. Ostenfeld and M. Pedersen, "Cryogenic in-vacuum undulator at Danfysik," in Proceedings of IPAC2010, Kyoto, Japan, 3093, WEPD006. Note that a later publication, Ref. 20, describes the device as being 114.5 periods long.

[20] Z. Patel, E.C.M. Rial, A. George, S. Milward, A.J. Rose, R.P. Walker, and J.H. Williams, "Insertion devices at Diamond Light Source: a retrospective plus future developments," in Proceedings of IPAC2017, Copenhagen, Denmark, 1592, TUPAB116.

[21] C. Kitegi, J. Chavanne, D. Cognie, P. Elleaume, F. Revol, C. Penel, B. Plan, and M. Rossat, "Development of a cryogenic permanent magnet in-vacuum undulator at the ESRF," in Proceedings of EPAC2006, Edinburgh, Scotland, 3559, THPLS119.

[22] J. Chavanne, M. Hahn, R. Kersevan, C. Kitegi, C. Penel, and F. Revol, "Construction of a cryogenic permanent magnet undulator at the ESRF," in Proceedings of EPAC2008, Genoa, Italy, 2243. WEPC105.

[23] J. Chavanne, G. Lebec, C. Penel, F. Revol, C. Kitegi, "First operation experience with a cryogenic permanent magnet undulator at the ESRF," in Proceedings of PAC2009, Vancouver, BC, Canada, 2414, WE5RFP067.

[24] J. Chavanne, G. Le Bec, C. Penel, F. Revol, and C. Kitegi, "Cryogenic Permanent Magnet Undulators," in Proceedings of the $10^{\text {th }}$ Int'l. Conf. Synchr. Rad. Instrum. 2009, AIP Conf. Proc 1234 (2010) 25; doi: 10.1063/1.3463185.

[25] J. Chavanne, C. Penel, and P. Elleaume, "Development and Operation of a Prototype Cryogenic Permanent Magnet Undulator at the ESRF," Synch. Rad. News 22 (2009) 34. doi: 10.1080/08940880903113968. 
[26] J. Chavanne, C. Benabderrahmane, G. Le Bec, and C. Penel, "Recent Developments in Insertion Devices at the ESRF: Working Toward Diffraction-Limited Storage Rings," Synch. Rad. News 28 (2015) 15. doi: 10.1080/08940886.2015.1037675.

[27] J. Chavanne, G. Le Bec, C. Penel, and F. Revol, "Recent progress in insertion devices at the ESRF," in Proceedings of IPAC2011, San Sebastian, Spain, 3245, THPC153.

[28] T. Tanabe, A. Blednykh, D. Harder, M. Lehecka, G. Rakowsky, and J. Skaritka, "Insertion device upgrade plans at the NSLS," in Proceedings of PAC 2005, Knoxville, TN, 1949.

[29] T. Tanabe, J. Ablett, L. Berman, D.A. Harder, S. Hulbert, M. Lehecka, G. Rakowsky, J. Skaritka, A. Deyhim, E. Johnson, J. Kulesza, and D. Waterman, "X-25 Cryo-ready In-vacuum Undulator at the NSLS," in Proceedings of the $9^{\text {th }}$ Int'l. Conf. Synchr. Rad. Instrum. 2006, AIP Conf. Proc. 879 (2007) 283, doi: $10.1063 / 1.2436056$.

[30] Y.Z. He, Q.G. Zhou, W. Zhang, H.F. Wang, and X.W. Zhang, "Research on Magnetic Properties of Nd(Pr)FeB Magnet for Cryogenic Permanent-Magnet Undulator of SSRF," IEEE Trans. Appl.

Supercond. 26 (2016) 0604204.

[31] C. Benabderrahmane, N. Béchu, P. Berteaud, M.E. Couprie, J.M. Filhol, C. Herbeaux, C. Kitegi, J.L. Marlats, K. Tavakoli, A. Mary, "Development of cryogenic undulator CPMU at Soleil," in Proceedings of EPAC2008, Genoa, Italy, 2225, WEPC098.

[32] C. Benabderrahmane, N. Béchu, P. Berteaud, M.E. Couprie, J.M. Filhol, C. Herbeaux, C. Kitegi, J.L. Marlats, K. Tavakoli, M. Valléau, D. Zerbib, "Development of a PrFeB cryogenic undulator at Soleil," in Proceedings of IPAC2010, Kyoto, Japan, 3096, WEPD007.

[33] C. Benabderrahmane, N. Béchu, P. Berteaud, L. Chapuis, M.E. Couprie, J.P. Daguerre, J.M. Filhol, C. Herbeaux, A. Lestrade, M. Louvet, J.L. Marlats, K. Tavakoli, M. Valléau, D. Zerbib, "Development of $\mathrm{Pr}_{2} \mathrm{Fe}_{14} \mathrm{~B}$ cryogenic undulator CPMU at Soleil," in Proceedings of IPAC2011, San Sebastián, Spain, 3233, THPC149.

[34] C. Benabderrahmane, N. Béchu, P. Berteaud, L. Chapuis, M.E. Couprie, J.P. Daguerre, J.M. Filhol, C. Herbeaux, A. Lestrade, M. Louvet, J.L. Marlats, K. Tavakoli, M. Valléau, D. Zerbib, "Development of $\mathrm{Pr}_{2} \mathrm{Fe}_{14} \mathrm{~B}$ cryogenic undulator CPMU at Soleil," in Proceedings of FEL2011, Shanghai, China, 523, THPA24.

[35] C. Benabderrahmane, P. Berteaud, M. Valléau, C. Kitegi, K. Tavakoli, N. Béchu, A. Mary, J.M. Filhol, M.E. Couprie, " $\mathrm{Nd}_{2} \mathrm{Fe}_{14} \mathrm{~B}$ and $\mathrm{Pr}_{2} \mathrm{Fe}_{14} \mathrm{~B}$ magnets characterisation and modelling for cryogenic permanent magnet undulator applications,” Nucl. Instrum. Meth. Phys. Res. A669 (2012) 1.

[36] T. Tanaka, T. Hara, T. Bizen, T. Seike, R. Tsuru, X. Maréchal, H. Hirano, M. Morita, H. Teshima, S. Nariki, N. Sakai, I. Hirabayashi, M. Murakami, and H. Kitamura, "Development of cryogenic permanent magnet undulators operating around liquid nitrogen temperature,” New J. Phys. 8 (2006) 287.

[37] T. Tanaka, R. Tsusu, T. Nakajima, T. Seike, and H. Kitamura, "In-situ undulator field measurement system with the SAFALI system," in Proceedings of FEL 2007, Novosibirsk, Russia, 468, WEPPH052.

[38] T. Tanaka, R. Tsuru, T. Nakajima, and H. Kitamura, "Magnetic characterization for cryogenic permanent-magnet undulators: a first result," J. Synch. Rad. 14 (2007) 416, doi: 10.1107/S0909049507026507. 
[39] R. Kinjo, T. Bizen, and T. Tanaka, “Undulator Development for SPring-8-II,” Synch. Rad. News 28 (2015) 45.

[40] J.C. Huang, H. Kitamura, C.K. Yang, Cheng-Hsing Chang, Cheng-Hsiang Chang, and C.S. Hwang, "Challenges of in-vacuum and cryogenic permanent magnet undulator technologies," Phys. Rev. Accel. Beams 20 (2017) 064801, doi: 10.1103/PhysRevAccelBeams.20.064801.

[41] T. Tanaka, T. Seike, A. Kagamihata, T. Schmidt, A. Anghel, M. Brügger, W. Bulgheroni, B. Jakob, H. Kitamura, "In situ correction of field errors induced by temperature gradient in cryogenic undulators," Phys Rev. ST - Accel. Beams 12 (2009) 120702.

[42] P.R. Willmott, D. Meister, S. J. Leake, M. Lange, A. Bergamaschi, M. Boge, M. Calvi, C. Cancellieri, N. Casati, A. Cervellino, Q. Chen, C. David, U. Flechsig, F. Gozzo, B. Henrich, S. JäggiSpielmann, B. Jakob, I. Kalichava, P. Karvinen, J. Krempasky, A. Lüdeke, R. Lüscher, S. Maag, C. Quitmann, M. L. Reinle-Schmitt, T. Schmidt, B. Schmitt, A. Streun, I. Vartiainen, M. Vitins, X. Wanga, and R. Wullschleger, "The Material Science beamline upgrade at the Swiss Light Source," J. Synch. Rad 20 (2013) 667.

[43] T. Schmidt, M. Calvi, and G. Ingold, "Undulators for the PSI Light Sources," Synch. Rad. News 28 (2015) 34. DOI:10.1080/08940886.2015.1037681.

[44] J. Chavanne, C. Benabderrahmane, G. Le Bec, and C. Penel, "Recent Developments in Insertion Devices at the ESRF: Working Toward Diffraction-Limited Storage Rings," Synch. Rad. News 28 (2015) 15. doi: 10.1080/08940886.2015.1037675.

[45] J. Chavanne, "Photon Sources Baseline for the ESRF-EBS," presentation slides from the ID2017 Undulator Workshop for Multibend Achromat Rings and Free Electron Lasers, held May 4-5, 2017, Berkeley, CA, USA, available at: https://sites.google.com/a/lbl.gov/id-workshop/program.

[46] J. Bahrdt, W. Frentrup, A. Gaupp, M. Scheer, R. Weingartner, F. O’Shea, F. Grüner, "Cryogenic Undulator for a Table Top FEL," in Proceedings of the $10^{\text {th }}$ Int'l. Conf. Synchr. Rad. Instrum. 2009, AIP Conf. Proc 1234 (2010) 499.

[47] J. Bahrdt, "Pushing the limits of short period permanent magnet undulators," in Proceedings of FEL2011, Shanghai, China, 435, THOAI1.

[48] F. Holy, A.R. Maier, B. Zeitler, R. Weingartner, S. Raith, N. Kajumba, M. El Ghazaly, W. Lauth, D. Krambrich, A. Gaupp, M. Scheer, J. Bahrdt, and F. Grüner, "First spectral measurements of a cryogenic high-field short-period undulator," Phys. Rev. ST - Accel Beams 17 (2014) 050704.

[49] J. Bahrdt \& C. Kuhn, "Cryogenic Permanent Magnet Undulator Development at HZB/BESSY II," Synch. Rad. News 28 (2015) 9. DOI:10.1080/08940886.2015.1037673.

[50] C. Kuhn, J. Bahrdt, A. Gaupp, M. Scheer, B. Schulz, "Development of Advanced Magnet Structures for Cryogenic In-Vacuum Permanent Magnet Undulators," in Proceedings of IPAC2014, Dresden, Germany, 2004, WEPRO029. 
[51] J. Bahrdt, “Cryogenic Undulator Development at HZB Including New In-Vacuum Field Measurement Tools," presentation slides from the ID2017 Undulator Workshop for Multibend Achromat Rings and Free Electron Lasers, held May 4-5, 2017, Berkeley, CA, USA, available at: https://sites.google.com/a/lbl.gov/id-workshop/program.

[52] J. Bahrdt, H.-J. Bäcker, W. Frentrup, C. Rethfeldt, M. Scheer, B. Schulz, and S. Gottschlich, “ $A$ canted double undulator system with a wide energy range for EMIL," in Proceedings of IPAC2015, 1442, TUPWA019.

[53] J. Bahrdt, J. Bakos, W. Frentrup, S. Gottschlich, S. Grimmer, C. Kuhn, C. Rethfeldt, A. RogoschOpolka, M. Scheer, B. Schulz, and L. Ziemann, "Status of the cryogenic undulator CPMU-17 for EMIL at BESSY II / HZB,” in Proceedings of IPAC2017, Copenhagen, Denmark, 1372, TUPAB026.

[54] Y.C. Zhang, S.P. Li, H.H. Lu, S.S. Sun, and Y.F. Yang, "Preliminary design of cooling system for a PrFeB-based cryogenic permanent magnet undulator prototype at IHEP," in Proceedings of IPAC2014, Dresden, Germany, 2743, WEPRI105.

[55] Y.F. Yang, H.H. Lu, S.C. Sun, and X.Z. Zhang, "Field error correction considerations of cryogenic permanent magnet (CPMU) for High Energy Test Facility (HEPS-TF)," in Proceedings of IPAC2016, Busan, Korea, 4038, THPOW041.

[56] H.H. Lu, W. Chen, Y.F. Yang, S.C. Chun, S.T. Zhao, X.Z. Zhang, L. Zhang, X.Y. Li, Z.Q. Li, L.L. Gong, and Y.J. Sun, "Development of a PrFeB cryogenic permanent magnet undulator (CPMU) prototype at IHEP," in Proceedings of IPAC2017, Copenhagen, Denmark, 1469, TUPAB064.

[57] S.C. Sun, H.H. Lu, Y.F. Yang, X.Y. Li, S.T. Zhao, X.Z. Zhang, L. Zhang, W. Chen, Z.Q. Li, L.L. Gong, and Y.J. Sun, "Mechanical Design of a cryogenic permanent magnet undulator at IHEP," in Proceedings of IPAC2017, Copenhagen, Denmark, 1475, TUPAB066.

[58] T. Tanabe, O. Chubar, D.A. Harder, M. Lehecka, J. Rank, G. Rakowsky, and C. Spataro, "Cryogenic Field Measurement of Pr2Fe14B Undulator and Performance Enhancement Options at the NSLS-II," in the Proceedings of the $10^{\text {th }}$ Int'l conf. on Synchr. Rad. Instrum. 2009, AIP Conf. Proc. 1234 (2010) 29, doi: $10.1063 / 1.3463195$.

[59] C.A. Kitegi, P. Cappadoro, O. Chubar, T. Corwin, D. Harder, P. He, H. Fernendez, G. Rakowsky, C. Rhein, J. Rank, T. Tanabe, "Development of a PrFeB Cryogenic Undulator at NSLS-II," in Proceedings of IPAC2012, New Orleans, LA, 762, MOPPP089.

[60] T. Tanabe, P. Cappadoro, T. Corwin, H. Fernandes, D.A. Harder, Y. Hidaka, D. Hidas, C. Kitegi, M. Musardo, and J. Rank, "Latest Experience on Insertion Devices at the National Synchrotron Light Source-II,”J. Vac. Soc. Japan 59 (2016) 205.

[61] C. Benabderrahmane, M. Valléau, P. Berteaud, K. Tavakoli, J.L. Marlats, R. Nagaoka, N. Béchu, D. Zerbib, P. Brunelle, L. Chapuis, D. Dallé, C. Herbeaux, A. Lestrade, M. Louvet, M.E. Couprie, "Development of a $2 \mathrm{~m} \mathrm{Pr}{ }_{2} \mathrm{Fe}_{14} \mathrm{~B}$ Cryogenic Permanent Magnet Undulator at SOLEIL," in Proceedings of $11^{\text {th }}$ Int'l. Conf. Synchr. Rad. Instrum. 2012, in J. of Phys.: Conf. Ser. 425 (2013) 032019. doi: $10.1088 / 1742-6596 / 425 / 3 / 032019$.

[62] M.-E. Couprie, F. Briquez, G. Sharma, C. F. Marteau, O. Marcouillé, P. Berteaud, T. El Ajjouri, J. Vétéran, L. Chapuis, and M. Valléau, "Cryogenic undulators," Proc. Of SPIE Vol. 9512 (2015) 951204, doi: $10.1117 / 12.2185510$. 
[63] M. Valléau, C. Benabderrahmane, F. Briquez, P. Berteaud, K. Tavakoli, D. Zerbib, L. Chapuis, F. Marteau, O. Marcouillé, T. El Ajjouri, J. Vétéran, G. Sharma, C. Kitegi, M. Tilmont, J. Da Silva Castro, M.-H. N'Guyen, N. Béchu, P. Rommeluère, M. Louvet, J.-M. Filhol, A. Nadji, C. Herbeaux, J.-L. Marlats, and M.-E. Couprie, "Development of Cryogenic Undulators with PrFeB Magnets at SOLEIL," in the Proceedings of $12^{\text {th }}$ Int'l Conf. on Synchr. Rad. Instrum. SRI2015, AIP Conf. Proc. 1741 (2016) 020024-1, doi: 10.1063/1.4952803.

[64] C. Benabderrahmane, M. Valléau, A. Ghaith, P. Berteaud, L. Chapuis, F. Marteau, F. Briquez, O. Marcouillé, J.-L. Marlats, K. Tavakoli, A. Mary, D. Zerbib, A. Lestrade, M. Louvet, P. Brunelle, K. Medjoubi, C. Herbeaux, N. Béchu, P. Rommeluere, A. Somogyi, O. Chubar, C. Kitegi, and M.-E. Couprie, "Development and operation of a Pr $2 \mathrm{Fe} 14 \mathrm{~B}$ based cryogenic permanent magnet undulator for a high spatial resolution x-ray beam line," Phys. Rev. Accel. Beams 20 (2017) 033201.

[65] A. Ghaith, M. Valléau, F. Briquez, G. Sharma, F. Marteau, P. Berteaud, C. Kitegi, M. Tilmont, J. DaSilva Castro, K. Tavakoli, J.M. Dubuisson, N. Béchu, C. Herbeaux, M. Sebdaoui, O. Marcouillé, F. Blache, A. Lestrade, A. Somogyi, M.E. Couprie, and C. Benabderrahmane, "Progress of Pr2Fe14B based hybrid cryogenic undulators at SOLEIL," in Proceedings of IPAC2017, Copenhagen, Denmark, 1213, TUOAA3.

[66] M.-E. Couprie, M. Valléau, F. Briquez, A. Ghaith, G. Sharma, P. Berteaud, C. Benabderrahmane, F Marteau, O. Marcouillé, C. Kitégi, J. Vétéran, F. Blache, P. Brunelle, K. Tavakoli, M. Tilmont, D. Zerbib, A. Mary, J. Da Silva, N. Béchu, C. Herbeaux, P. Rommeluère, A. Somogyi, K. Medjoubi, and M. Louvet, "Cryogenically Cooled Undulators," presentation slides from the ID2017 Undulator Workshop for Multibend Achromat Rings and Free Electron Lasers, held May 4-5, 2017, Berkeley, CA, USA, available at: https://sites.google.com/a/lbl.gov/id-workshop/program.

[67] M.E. Couprie, C. Benabderrahmane, P. Berteaud, C. Bourassin-Bouchet, F. Bouvet, F. Briquez, L. Cassinari,L. Chapuis, M. Diop, J. Daillant, M. El Ajjouri, C. Herbeaux, N. Hubert, M. Labat, P. Lebasque, A. Lestrade, A. Loulergue, P. Marchand, O. Marcouillé, J. L. Marlats, C. Miron, P. Morin, A. Nadji, F. Polack, F. Ribeiro, J. P. Ricaud, P. Roy, K. Tavakoli, M. Valléau, D. Zerbib, S. Bielawski, C. Evain, E. Roussel, C. Szwaj, G. Lambert, V. Malka, R. Lehe, A. Rousse, C. Thaury, G. Devanz, C. Madec, A. Mosnier, D. Garzella, B. Carré, N. Delerue, X. Davoine, A. Dubois, and J. Lüning, "The status of LUNEX5 project," in Proceedings of FEL2014, Basel, Switzerland, 574, TUP087.

[68] J.-C. Huang, H. Kitamura, C.-Y. Kuo, C.-K. Yang, C.-H. Chang, Y.-T. Yu, Y.-Y.- Lin, C.-S. Hwang, "Design of a Magnetic Circuit for a Cryogenic Undulator in Taiwan Photon Source," in the Proceedings of $12^{\text {th }}$ Int'l Conf. on Synchr. Rad. Instrum. SRI 2015, AIP Conf. Proc. 1741 (2016) 020016, doi: $10.1063 / 1.4952795$.

[69] J.C. Huang, C.K. Yang, C.H. Chang, C.S. Yang, T.Y. Chung, J.C. Jan, and C.S. Hwang, "Development of a cryogenic permanent magnet undulator for the TPS," in the Proceedings of IPAC2017, Copenhagen, Denmark, 1562, TUPAB106.

[70] J.C. Huang, H. Kitamura, C.K. Yang, Cheng-Hsing Chang, Cheng-Hsiang Chang, and C.S. Hwang, "Challenges of in-vacuum and cryogenic permanent magnet undulator technologies," Phys. Rev. Accel. Beams 20 (2017) 064801, doi: 10.1103/PhysRevAccelBeams.20.064801.

[71] S. Casalbuoni, A. Bernhard, R. Frahm, B. Griesebock, U. Haake, M. Hagelstein, M. Kläser, B. Kostka, A.S. Müller, R. Rossmanith, Th. Schneider, F. Schoeck, E. Steffens, M. Weisser, D. Wollmann, and T. Baumbach, "One year operation of a superconducting undulator in the storage ring ANKA," in the Proceedings of the $9^{\text {th }}$ Int'l Conf. on Synchr. Rad. Instrum. SRI2006, AIP Conf. Proc. 879 (2007) 301. 
[72] S. Casalbuoni, N. Glamann, A.W. Grau, T. Holubek, D. Saez de Jauregui, C. Boffo, Th.A. Gerhard, M. Turenne, and W. Walter, "Field quality of $1.5 \mathrm{~m}$ long conduction cooled superconducting undulator coils with $20 \mathrm{~mm}$ period length," in Proceedings of IPAC2017, Copenhagen, Spain, 1395, TUPAB035.

[73] A. Grau, S. Casalbuoni, N. Glamann, T. Holubek, D. Saez de Jauregui, C. Boffo, Th. Gerhard, M. Turenne, and W. Walter, "Training and characterization of $1.5 \mathrm{~m}$ long conduction cooled superconducting undulator coils with $20 \mathrm{~mm}$ period length," in Proceedings of IPAC2017, Copenhagen, Spain, 1395, TUPAB036.

[74] S. Casalbuoni, N. Glamann, A. Grau, T. Holubek, C. Meuter, D. Saez de Jauregui, C. Boffo, Th. Gerhard, M. Turenne, and W. Walter, "Superconducting undulators at KIT," presentation slides from the ID2017 Undulator Workshop for Multibend Achromat Rings and Free Electron Lasers, held May 4-5, 2017, Berkeley, CA, USA, available at: https://sites.google.com/a/lbl.gov/id-workshop/program.

[75] M. Kasa, C. Doose, J. Fuerst, Y. Ivanyushenkov, and E. Gluskin, "Progress on the magnetic performance of planar superconducting undulators," in Proceedings of NAPAC 2016, Chicago, IL, USA, 477, TUB4CO04.

[76] Y. Ivanyushenkov, C. Doose, J. Fuerst, Q. Hasse, M. Kasa, Y. Shiroyanagi, and E. Gluskin, "Status of the development of superconducting undulators at the Advanced Photon Source," in Proceedings of IPAC2017, Copenhagen, Denmark, 2499, WEOCA3.

[77] Y. Ivanyushenkov, C. Doose, J. Fuerst, K. Harkay, Q. Hasse, M. Kasa, D. Skiadopoulos, E.M. Trakhtenberg, Y. Shiroyanagi, and E. Gluskin, "Development and performance of 1.1-m long superconducting undulator at the Advanced Photon Source," in Proceedings of IPAC2015, Richmond, VA, USA, 1794, TUPJE068. 